\title{
Comparisons of polar processing diagnostics from 34 years of the ERA-Interim and MERRA reanalyses
}

\author{
Z. D. Lawrence ${ }^{1}$, G. L. Manney ${ }^{2,1}$, K. Minschwaner ${ }^{1}$, M. L. Santee ${ }^{3}$, and A. Lambert ${ }^{3}$ \\ ${ }^{1}$ New Mexico Institute of Mining and Technology, Socorro, NM, USA \\ ${ }^{2}$ NorthWest Research Associates, Socorro, NM, USA \\ ${ }^{3}$ Jet Propulsion Laboratory, California Institute of Technology, Pasadena, CA, USA
}

Correspondence to: Z. D. Lawrence (zlawrenc@nmt.edu)

Received: 24 October 2014 - Published in Atmos. Chem. Phys. Discuss.: 12 December 2014

Revised: 19 March 2015 - Accepted: 22 March 2015 - Published: 13 April 2015

\begin{abstract}
We present a comprehensive comparison of polar processing diagnostics derived from the National Aeronautics and Space Administration (NASA) Modern Era Retrospective-analysis for Research and Applications (MERRA) and the European Centre for Medium-Range Weather Forecasts (ECMWF) Interim Reanalysis (ERAInterim). We use diagnostics that focus on meteorological conditions related to stratospheric chemical ozone loss based on temperatures, polar vortex dynamics, and air parcel trajectories to evaluate the effects these reanalyses might have on polar processing studies. Our results show that the agreement between MERRA and ERA-Interim changes significantly over the 34 years from 1979 to 2013 in both hemispheres and in many cases improves. By comparing our diagnostics during five time periods when an increasing number of higher-quality observations were brought into these reanalyses, we show how changes in the data assimilation systems (DAS) of MERRA and ERA-Interim affected their meteorological data. Many of our stratospheric temperature diagnostics show a convergence toward significantly better agreement, in both hemispheres, after 2001 when Aqua and GOES (Geostationary Operational Environmental Satellite) radiances were introduced into the DAS. Other diagnostics, such as the winter mean volume of air with temperatures below polar stratospheric cloud formation thresholds $\left(V_{\mathrm{PSC}}\right)$ and some diagnostics of polar vortex size and strength, do not show improved agreement between the two reanalyses in recent years when data inputs into the DAS were more comprehensive. The polar processing diagnostics calculated from MERRA and ERA-Interim agree much better than those calculated from earlier reanalysis data sets. We still, however, see fairly large differences in many of the diagnostics in years
\end{abstract}

prior to 2002, raising the possibility that the choice of one reanalysis over another could significantly influence the results of polar processing studies. After 2002, we see overall good agreement among the diagnostics, which demonstrates that the ERA-Interim and MERRA reanalyses are equally appropriate choices for polar processing studies of recent Arctic and Antarctic winters.

\section{Introduction}

The depletion of stratospheric ozone in the polar regions is a consequence of chemical processing that is strongly dependent upon meteorological conditions (e.g., Solomon, 1999). This polar processing takes place within the stratospheric vortices that form over the Earth's poles in the fall and persist into spring. These polar vortices act as strong barriers to transport and mixing of air across their edges (e.g., Schoeberl et al., 1992; Manney et al., 1994a, 2011; Strahan et al., 2013; and references therein), providing a pool of isolated air inside them where polar processing can take place (e.g., Schoeberl et al., 1992). The lower stratospheric processes that lead to chemical ozone destruction include the development of polar stratospheric clouds (PSCs), denitrification via sedimentation of PSCs, and conversion of inert chlorine reservoirs to ozone-destroying forms by reactions on the surfaces of PSCs (e.g., Solomon, 1999). Because these phenomena depend critically on temperatures and winds throughout the lower stratosphere (e.g., WMO, 2011, 2015; Brakebusch et al., 2013; Manney et al., 2011; Sinnhuber et al., 2011; and references therein), diagnostics related to ozone loss require fields (e.g., winds) and data coverage (e.g., 
vertically resolved, hemispheric, multiannual) that cannot be obtained from individual measurement systems such as satellites and radiosonde networks. As a result, the global analyses of meteorological fields provided by data assimilation systems (DAS) that combine many of these measurements are invaluable for polar processing and ozone loss studies. Numerous such DAS analyses are now available, facilitating both observational and modeling studies of polar processing (e.g., WMO, 2011, 2015, and references therein). However, variations in the representation of meteorological conditions are expected because of differences in the model formulations and resolutions, assimilation methods, and assimilated products (Fujiwara et al., 2012). The existence of these differences raises the possibility of conflicting results and conclusions among similar studies conducted using different DAS analyses.

Polar ozone loss has been the subject of extensive research aimed at quantifying its dependence on dynamical and chemical processes (e.g., WMO, 2015). Diagnostics using meteorological conditions to assess the potential for chemical processing, especially PSC formation and chlorine activation, are commonly used. Some of these diagnostics, such as the volume of air below PSC temperature thresholds ( $V_{\mathrm{PSC}}$ ), have been found to have strong links to total column ozone depletion (e.g., Rex et al., 2004; Tilmes et al., 2006; Harris et al., 2010). While some studies have linked changes in $V_{\mathrm{PSC}}$ to an expectation of colder winters and greater ozone loss in the Arctic to global climate change (Rex et al., 2004, 2006), others do not support this conclusion (Hitchcock et al., 2009; Pommereau et al., 2013; Rieder and Polvani, 2013). Climate model projections of future ozone loss are also highly uncertain (e.g., Charlton-Perez et al., 2010). Thus, the prediction of future ozone loss is still problematic, and improvements in such predictions will require better understanding of the uncertainties and potential biases in representation of the meteorological conditions upon which polar processing depends so critically in commonly used DAS.

Previous studies have recognized the importance of understanding the sensitivity of polar processing and ozone loss quantification to different data sets: Davies et al. (2002) showed that two SLIMCAT chemical transport model (CTM) runs driven by horizontal winds and temperatures from the ECMWF (European Centre for Medium-Range Weather Forecasts) and Met Office DAS led to significantly different patterns of denitrification and chlorine activation and consequently large differences in ozone loss of nearly $20 \%$. Similarly, Santee et al. (2002) found significant discrepancies in PSC formation and composition between model runs that used Met Office temperatures with and without a $3 \mathrm{~K}$ reduction. Sinnhuber et al. (2011) found that reducing the temperatures from the ECMWF operational analyses by $1 \mathrm{~K}$ in CTM runs for the 2010/2011 Arctic winter resulted in a substantial increase in ozone loss. Brakebusch et al. (2013) reduced GEOS-5 (Goddard Earth Observing System model, version 5) temperatures by $1.5 \mathrm{~K}$ in a Whole Atmosphere Commu- nity Climate Model simulation of ozone for the 2004/2005 Arctic winter; applying this temperature bias improved the agreement of simulated ozone with measurements from the Aura Microwave Limb Sounder satellite instrument. In other cases, some DAS analyses have been shown to have significant shortcomings for use in polar processing and ozone loss research. For example, Manney et al. (2005b) and Feng et al. (2005) discuss many issues with polar temperatures from the ECMWF 40-year reanalysis (ERA-40), including periods with large spurious vertical oscillations in polar winter temperature profiles (e.g., Simmons et al., 2005). In intercomparisons of temperature diagnostics related to Arctic polar processing of several meteorological analyses, Manney et al. (2003) found that the area with temperatures below PSC thresholds varied by up to $50 \%$ between different analyses, and potential PSC lifetimes differed by several days. Manney et al. (2005a) argued that several reanalyses (the data sets referred to therein as the National Centers for Environmental Prediction and National Center for Atmospheric Research (NCEP-NCAR) reanalysis, NCEP-DOE reanalysis-2, and ERA-40) were unsuitable for stratospheric and polar processing studies.

Since the above-mentioned studies, significant advances have been made in modeling and data assimilation, and several additional data sets have become available for constraining the DAS (e.g., Dee et al., 2011; Rienecker et al., 2011; Lahoz and Schneider, 2014; and references therein). Longterm reanalysis systems have become much more widely used, and the long-term records of global meteorology based on observational data that they provide are increasingly critical for climate studies. The growing use of reanalysis data sets demands intercomparisons that quantify the differences between them. While numerous intercomparisons have been done (see, e.g., https://reanalyses.org/atmosphere/ inter-reanalysis-studies-0), most focus primarily on tropospheric and/or near-surface processes. A few studies have also compared tropical upper tropospheric processes in commonly used reanalyses (e.g., Schoeberl and Dessler, 2011; Fueglistaler et al., 2013). Rieder and Polvani (2013) showed calculations of one polar processing diagnostic, $V_{\mathrm{PSC}}$, from three reanalyses. However, no comprehensive intercomparisons of diagnostics pertinent to polar processing in the winter lower stratosphere have been done for the reanalyses that are currently in widespread use. In this paper, we present intercomparisons of polar processing diagnostics derived from the National Aeronautics and Space Administration (NASA) Modern Era Retrospective analysis for Research and Applications (MERRA) and the ECMWF Interim Reanalysis (ERA-Interim). These data sets were chosen for this initial study because of their extensive application in numerous stratospheric studies. Rather than focusing on specific seasons and/or a single hemisphere, we present most of our diagnostics for the 1979-2013 record of the reanalyses for both Arctic and Antarctic winters. We examine the potential correlation of differences between the analyses over the 
above time period with the timing of changes in observations ingested by their DAS.

In general, it can be difficult to directly assess the accuracy of reanalyses because there are few independent (i.e., not used in the assimilation) measurements that span the full periods of the available reanalysis data. In the context of polar processing, this difficulty is far greater because most of the commonly used polar processing diagnostics require temperature data with spatial coverage greater than ground-based measurements, such as those from the Network for the Detection of Atmospheric Composition Change (see www.ndacc.org), can provide. Large-scale independent temperature measurements can be obtained from some satellite instruments like the Upper Atmosphere Research Satellite Microwave Limb Sounder (MLS), Aura MLS, and Atmospheric Chemistry Experiment Fourier transform spectrometer (ACE-FTS), but these measurements typically have biases of their own (e.g., Schwartz et al., 2008; Sica et al., 2008). Many polar processing diagnostics also require information about the polar vortex from potential vorticity (PV) data, which cannot be provided by any measurement system. The degree of agreement between reanalyses is thus an important indicator of their inherent uncertainties and the potential impact of those uncertainties on polar processing studies. Therefore, one of the intentions of this study is to show when the use of multiple reanalyses is recommended to estimate uncertainties of quantities related to polar processing and when the use of a single reanalysis is sufficient.

In Sect. 2 we describe the data sets, relevant aspects of the assimilated observations, and the diagnostics and comparison methods we use. The results, presented in Sect. 3, comprise comparisons of polar processing diagnostics based on temperatures, polar vortex dynamics, and trajectory-based temperature histories. Our conclusions are then summarized and discussed in Sect. 4.

\section{Data and analysis}

\subsection{NASA MERRA}

MERRA is a global atmospheric reanalysis that uses version 5.2 of the GEOS model and assimilation system. It utilizes a combination of 3D-Var assimilation and incremental analysis update (Bloom et al., 1996) to apply corrections from analysis to the forecast model. The MERRA system operates natively on a $0.5 \times 0.667^{\circ}$ latitude/longitude grid $(361 \times 540$ grid points) and uses a hybrid sigma-pressure scheme with 72 vertical levels up to $0.01 \mathrm{hPa}$; the vertical resolution in the lower stratosphere is near $1 \mathrm{~km}$. Further details about the MERRA system are given by Rienecker et al. (2011). The MERRA data files available from NASA's Global Modeling and Assimilation Office (GMAO) are described by Lucchesi (2012). Except where specified otherwise, the MERRA temperature data used here are from instantaneous daily files at 12:00 UT on the model levels and grid. However, the potential vorticity data from MERRA are available from GMAO only on a reduced $1 \times 1.25^{\circ}$ latitude/longitude grid $(181 \times 288$ grid points) with 42 pressure levels up to $0.1 \mathrm{hPa}$; for the purposes of this study, MERRA PV is linearly interpolated to match the model levels and grid as was done in Manney et al. (2011). Although these interpolations of the MERRA PV data cause some smoothing in the resulting PV fields, they preserve the strong PV gradients that define the polar vortex edge. All of the PV-based polar processing diagnostics we use depend strongly on the vortex edge and PV gradients (see Sect. 2.4.1), so these diagnostics are unlikely to be significantly affected by the errors introduced from interpolating MERRA PV to the model grid and levels.

\subsection{ECMWF Interim Reanalysis}

ERA-Interim (hereinafter ERA-I) is another global atmospheric data assimilation system. The goal of the ERA-I project was to improve upon ECMWF's previous reanalysis, ERA-40, in advance of their planned next-generation reanalysis. It uses $12 \mathrm{~h}$ cycles of $4 \mathrm{D}$-Var assimilation and a T255 spectral model with 60 vertical levels; the vertical resolution in the lower stratosphere is comparable to that of MERRA. The ERA-I system is described in detail by Dee et al. (2011), and the data sets provided by ECMWF from the ERA-I archive are described by Berrisford et al. (2009). Here, ERA-I data are used on the highest resolution regular latitude/longitude grid publicly available at $0.75 \times 0.75^{\circ}$ $(241 \times 480$ grid points $)$ on the 60 model vertical levels that go up to $0.1 \mathrm{hPa}$; this grid has spacing closest to that of the Gaussian grid associated with the spectral model. As with MERRA, unless stated otherwise, the ERA-I temperature and PV data used in this study are instantaneous at 12:00 UT. However, in this case the PV is derived from the provided relative vorticity, temperature, and pressure fields.

\subsection{Timelines of assimilated observations}

Since satellite observations are the primary constraint on reanalysis products at stratospheric levels, it is useful to consider how the data evolve with the introduction of new missions and instruments: Pawson (2012) noted the effect of the TOVS (Tiros Operational Vertical Sounder) to Advanced TOVS (ATOVS) transition in 1998 on middle and upper stratospheric global temperature anomalies from MERRA and ERA-I. At $5 \mathrm{hPa}$, he shows that ERA-I temperatures dropped suddenly by about $2 \mathrm{~K}$, while in MERRA the mean annual cycle changed noticeably. Pawson asserts that these distinct discontinuities suggest that more work is needed to properly handle Stratospheric Sounding Unit radiances in reanalyses. Fueglistaler et al. (2013) mention that the introduction of COSMIC (Constellation Observing System for Meteorology, Ionosphere, and Climate) GPSRO (Global Positioning Satellite Radio Occultation) temperature data into ERA-I in 2006 caused a temperature shift in the tropics of about 
Table 1. Names of abbreviated instruments and satellites assimilated in ERA-Interim and MERRA.

\begin{tabular}{ll}
\hline Acronym & Full name \\
\hline AIRS & Atmospheric InfraRed Sounder \\
AMSR & Advanced Microwave Scanning Radiometer \\
AMSU & Advanced Microwave Sounding Unit \\
ATOVS & Advanced TIROS Operational Vertical Sounder \\
CHAMP & CHAllenging Minisatellite Payload \\
COSMIC & Constellation Observing System for Meteorology, \\
& Ionosphere, and Climate \\
GOES & Geostationary Operational Environmental Satellite \\
HIRS & High-resolution Infrared Radiation Sounder \\
MHS & Microwave Humidity Sounder \\
MSU & Microwave Sounding Unit \\
SSM/I & Special Sensor Microwave Imager/Sounder \\
SSU & Stratospheric Sounding Unit \\
TOVS & TIROS Operational Vertical Sounder \\
\hline
\end{tabular}

$0.5 \mathrm{~K}$ at $100 \mathrm{hPa}$. Simmons et al. (2014) discuss in detail the various effects of the different satellite missions and instruments on ERA-I temperature data and perform intercomparisons with MERRA and the Japanese 55-year Reanalysis (JRA55).

In many of our diagnostics, we examine how well MERRA and ERA-I agree over the 1979 to 2013 time period. The observations assimilated in the reanalyses change dramatically over this period, and in some cases there are differences between MERRA and ERA-I in the timing of the changes and the observations included. Figure 1 shows a comparison of the primary satellite data sets assimilated in MERRA and ERA-I, compiled from information in Rienecker et al. (2011), Dee et al. (2011), and Simmons et al. (2014). (See Table 1 for the full names of the instruments/satellites listed in Fig. 1 and throughout this paper.) The colored regions indicate periods of years between which the data input streams change significantly; in other words, marking times when the differences between MERRA and ERA-I might be expected to shift. In this case, we have chosen boundaries at 1987 (when SSM/I was introduced), 1998 (when ATOVS was introduced), 2002 (inclusion of CHAMP in ERA-I, and AIRS and AMSU-A in both reanalyses), and 2007 (when COSMIC was included in ERA-I).

\subsection{Polar processing diagnostics and intercomparisons}

The diagnostics we use are designed to assess a wide range of conditions related to polar processing; many of them have been described previously (Manney et al., 2003, 2005a, 2011). These diagnostics fall into three categories, focusing on assessment of temperatures, vortex characteristics, or air parcel histories. Taken together, the diagnostics used here provide a comprehensive evaluation of the meteorological conditions pertinent to chemical processing and ozone destruction in the polar stratosphere. Because our focus is on assessing the effects of reanalysis differences on studies of polar processing that takes place in the lower stratosphere, we focus in this paper on isentropic levels below about $600 \mathrm{~K}$ (approximately $25 \mathrm{~km}$, or $30 \mathrm{hPa}$ ).

\subsubsection{Temperature and vortex diagnostics}

The importance of stratospheric temperatures to the formation of PSCs gives rise to the need for temperature diagnostics. Although some recent studies have suggested that liquid PSCs play a dominant role in activating chlorine (e.g., Wegner et al., 2012; Wohltmann et al., 2013), the formation temperatures of solid nitric acid trihydrate (NAT, Hanson and Mauersberger, 1988) and ice particles remain convenient thresholds for the initiation of chlorine activation processes. In this study, we examine daily 12:00 UT minimum temperatures and calculations of area with temperatures below PSC thresholds (henceforth $T_{\min }$ and $A_{\text {PSC }}$, respectively). We also use diagnostics derived from $T_{\min }$ and $A_{\mathrm{PSC}}$, such as the number of days during a polar winter with temperatures below PSC thresholds, and the volume of stratospheric air below PSC thresholds ( $\left.V_{\mathrm{PSC}}\right)$. For $A_{\mathrm{PSC}}$, vertical temperature profiles of the NAT and ice thresholds are derived using climatological profiles of $\mathrm{HNO}_{3}$ and $\mathrm{H}_{2} \mathrm{O}$ mixing ratios on six-per-decade pressure levels (Manney et al., 2003) and interpolating to approximately co-located potential temperature surfaces (e.g., the 56.2 and $31.6 \mathrm{hPa}$ levels are referenced to 490 and $580 \mathrm{~K}$, respectively). $V_{\mathrm{PSC}}$ is calculated by vertically integrating eight potential temperature levels between 390 and $580 \mathrm{~K}$ using the altitude approximation introduced by Knox (1998), which gives altitudes for these levels that are $\sim 1.1 \mathrm{~km}$ apart. Altitude approximations are typically used for calculations of $V_{\mathrm{PSC}}$, and these calculations have been shown to be relatively insensitive to the particular approximation used (e.g., Rex et al., 2004; Manney et al., 2011; Rieder and Polvani, 2013).

Since the polar vortex provides the "containment vessel" within which polar chemical processing takes place (e.g., Schoeberl et al., 1992), we also compare diagnostics that characterize vortex strength and size. These include daily 12:00 UT maximum PV gradients (henceforth MPVGs; one measure of vortex strength, e.g., Manney et al., 2011, and references therein) and the area of a hemisphere covered by the vortex (henceforth $A_{\text {vort }}$ ). In addition to the total area of the vortex, we also calculate the area of the vortex that receives sunlight each day, since the photochemical processes involved in chlorine catalyzed ozone depletion require sunlight (e.g., Solomon, 1999). Finally, we vertically integrate $A_{\text {vort }}$ in the same manner as $A_{\text {PSC }}$ to derive the vortex fraction of low-temperature air (i.e., $V_{\mathrm{PSC}} / V_{\text {vort }}$ ). In all cases we use isentropic surfaces and scale PV into "vorticity units" $\left(\mathrm{s}^{-1}\right)$ (Dunkerton and Delisi, 1986; Manney et al., 1994b). MPVG is calculated as described by Manney et al. (1994a): scaled PV (sPV) is numerically differentiated with respect to equivalent latitude (i.e., the value of the latitude circle 


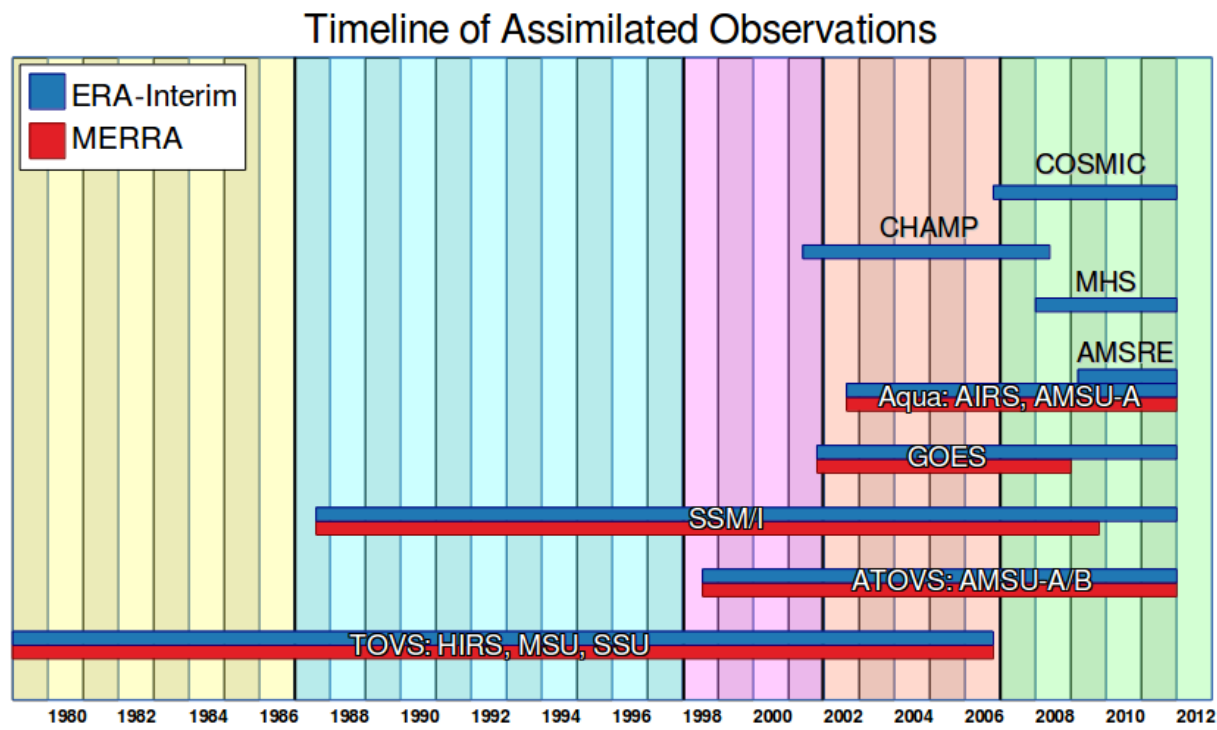

Figure 1. Timeline of satellite and GPSRO measurements assimilated in MERRA and ERA-Interim, organized by missions (when applicable) and instruments. Colored periods indicate regions of interest for intercomparisons defined by significant changes in both data streams. We use yellow, cyan, magenta, orange, and green to represent the years within 1979-1986, 1987-1997, 1998-2001, 2002-2006, and 2007-2013, respectively.
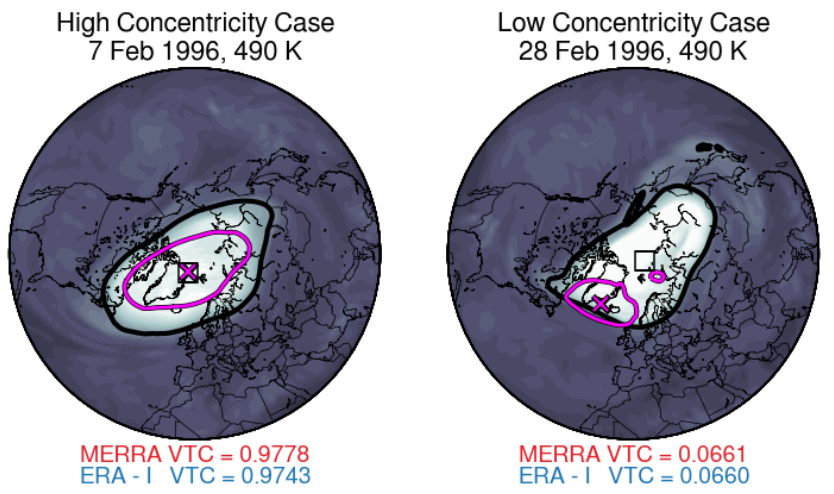

Figure 2. Maps showing example cases when MERRA data indicate high (left) and low (right) values of vortex-temperature concentricity (VTC) at $490 \mathrm{~K}$. The background field is potential vorticity from MERRA, and the thick black lines represent the vortex edge as defined by the $1.4 \times 10^{-4} \mathrm{~s}^{-1} \mathrm{sPV}$ contour. The magenta lines represent cold regions where temperatures (also from MERRA) are below $T_{\mathrm{NAT}}$. The black squares and the magenta $\mathrm{X}$ marks are plotted at the centroid locations of the polar vortex and cold regions, respectively. For convenience, the corresponding values of VTC from MERRA (red) and ERA-I (blue) are shown below the maps.

enclosing the same area as a given PV contour); if the maximum gradient occurs at an equivalent latitude poleward of $\pm 80^{\circ}$, we consider the vortex to be undefined and set the maximum gradient equal to zero. To calculate the area of the polar vortex, we use the $1.4 \times 10^{-4} \mathrm{~s}^{-1} \mathrm{sPV}$ contour as a simple proxy for the vortex edge (e.g., Manney et al., 2007). The total area of the vortex is then the area of the contour.
The sunlit area is the area inside the vortex-edge contour that is equatorward of the daily polar night latitude at 12:00 UT.

\subsubsection{Advanced dynamical diagnostics}

One of our diagnostics is best described as a hybrid temperature-vortex diagnostic. It is the concentricity of the polar vortex with regions of temperatures below the NAT PSC threshold (henceforth referred to as vortex-temperature concentricity, or VTC). VTC is adapted from the concept of concentricity as discussed by Mann et al. (2002). We calculate it using the simple formula

$\mathrm{VTC}=1-\frac{\text { GCDist(Vortex Centroid, Cold Region Centroid })}{\text { GCDist(Pole, Equiv. Lat. of Vortex Edge })}$,

where $\operatorname{GCDist}(x, y)$ is the great circle distance between $x$ and $y$. This definition provides an intuitive picture of the vortex/temperature relationships under extreme conditions: a maximum value of 1 for collocated centroids (completely concentric) and values less than or equal to 0 for a cold region centroid approximately at or outside the vortex edge. Centroid locations are calculated as described by Mitchell et al. (2011) and Seviour et al. (2013), with the $1.4 \times 10^{-4} \mathrm{~s}^{-1}$ sPV and pressure-dependent NAT PSC temperatures as the edge values for the vortex and cold regions, respectively. For simplicity, we only calculated one centroid for each field. This means that, for example, during vortex-split events, offspring vortices were not characterized individually. Under conditions where multiple closed contours exist, VTC values may be calculated using centroids that lie completely outside of the regions of interest. While it would be important 


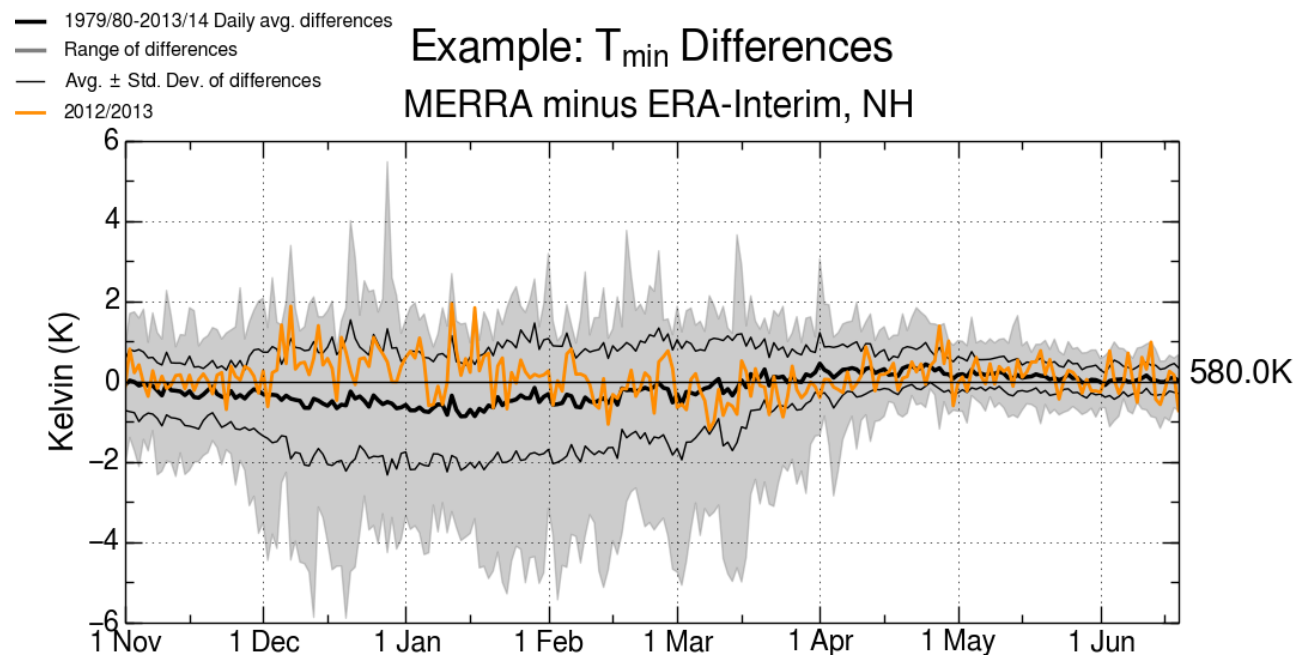

Figure 3. An example time series of the differences that are calculated for the daily diagnostics $\left(T_{\min }, A_{\mathrm{PSC}}\right.$, etc.) that are in turn used to calculate the monthly comparison period average differences (monthly CPADs). This case shows the differences in $T_{\text {min }}$ between MERRA and ERA-I at $580 \mathrm{~K}$ for the 2012/2013 Arctic winter in orange, with the range of differences over all NH winters from 1979/80 to 2013/14 shown by the grey envelope. The thick black line represents the average daily differences over the 1979/80-2013/14 period, while the thin black lines show 1 standard deviation. Since the average daily differences vary over the season shown, we compute the monthly CPADs as the monthly means of these average daily differences. Doing so for this example would give monthly CPADs for the 1979/80-2013/14 period; for the rest of this paper, we calculate them from the average daily differences of the five individual comparison periods defined in Fig. 1.

\section{$\mathrm{T}_{\min }$ Comparisons (@ $580 \mathrm{~K}$ )}
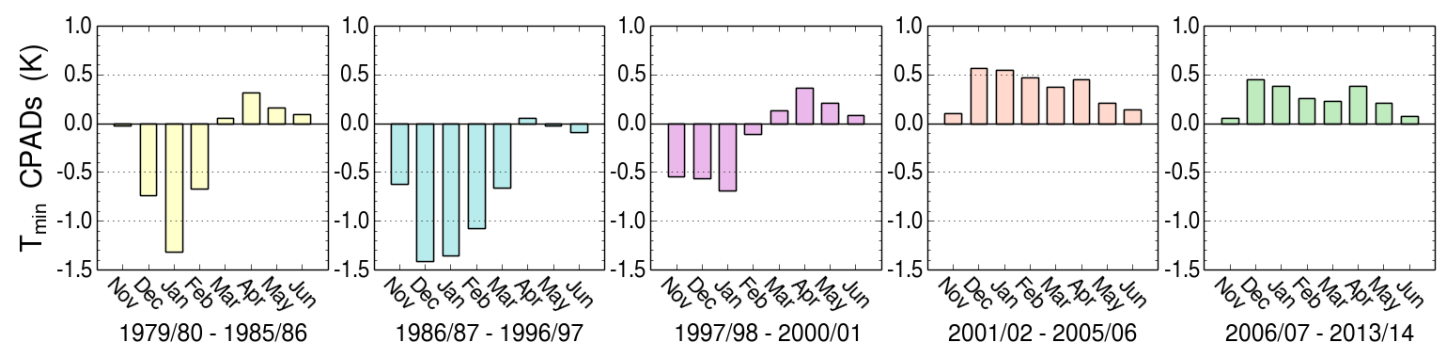

$\mathrm{NH}$
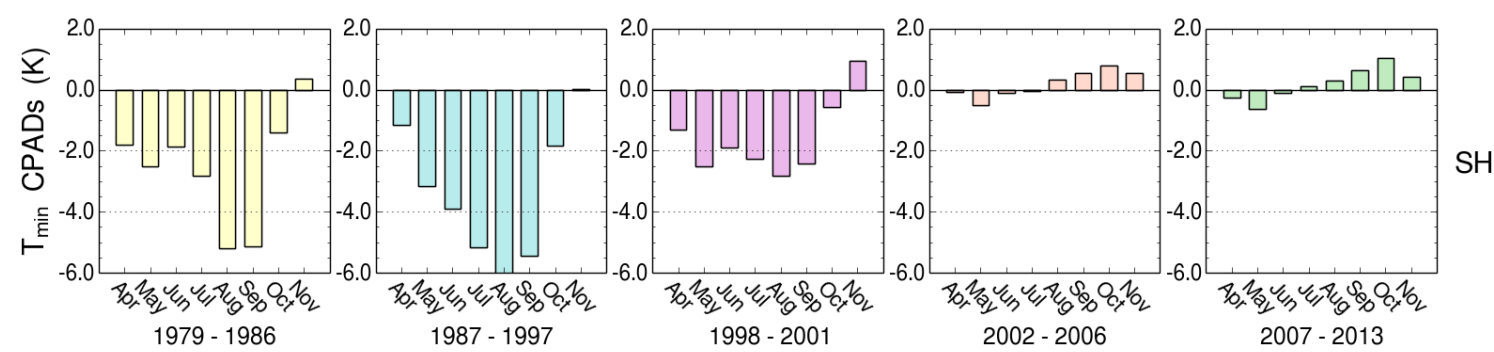

Figure 4. Monthly CPADs of $T_{\min }$ between MERRA and ERA-Interim at $580 \mathrm{~K}$ potential temperature for Arctic (top row) and Antarctic (bottom row) winters. The yellow, cyan, magenta, orange, and green colors used in the columns correspond to the colors of the comparison periods shown in Fig. 1, which represent 1979-1986, 1987-1997, 1998-2001, 2002-2006, and 2007-2013, respectively. The NH (SH) panels cover months from November to June (April to November). Note that the $T_{\min }(y$ axis) scales are different for each hemisphere.

to more accurately characterize split vortices for detailed dynamical studies, this simplification does not significantly affect the broad climatological comparisons we are focusing on here. Figure 2 shows an example of our VTC diagnostic using maps of MERRA PV at $490 \mathrm{~K}$ with the centroids of the polar vortex (the black squares) and cold regions (magenta X marks) overlaid. The dates shown were chosen for their extremes of VTC - one nearly concentric case (7 February 1996) when both MERRA and ERA-I have VTC close 

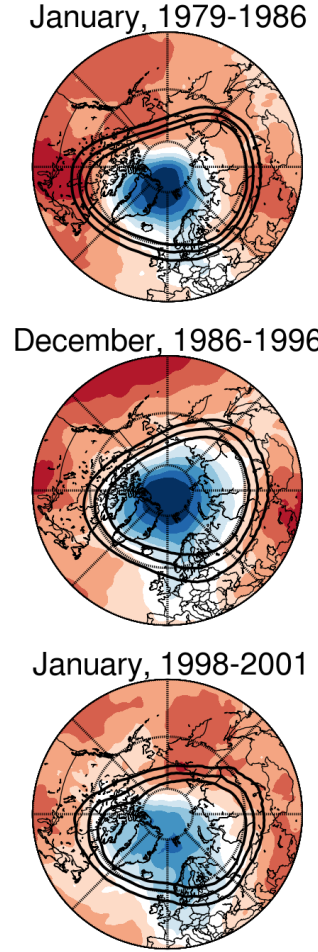

December, 2001-2005

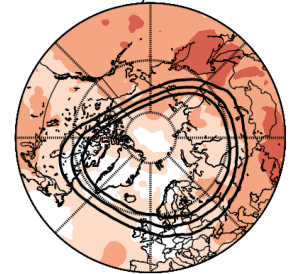

December, 2006-2013

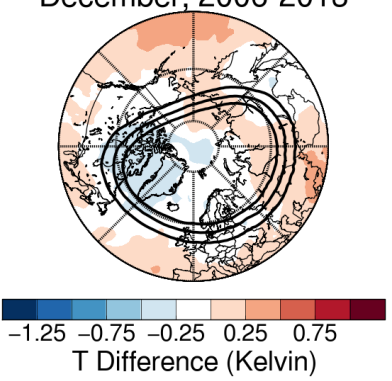

August, 1979-1986

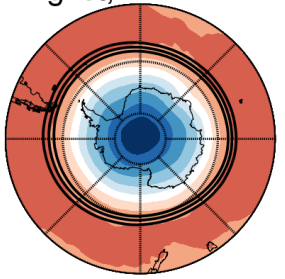

August, 1987-1997

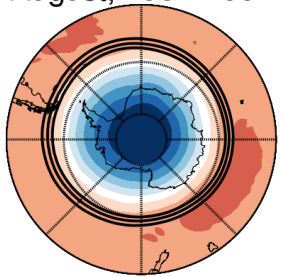

August, 1998-2001

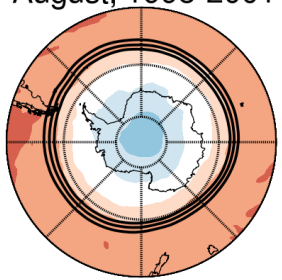

October, 2002-2006

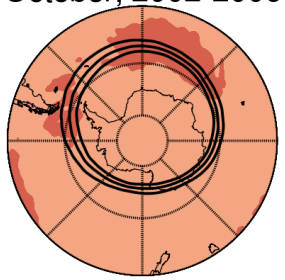

October, 2007-2013

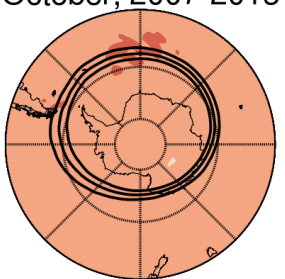

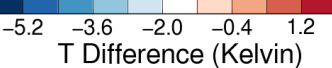

Figure 5. Maps of mean MERRA minus ERA-I 12:00 UT temperatures (averaged over the years listed) at $580 \mathrm{~K}$ potential temperature for the Arctic (left) and Antarctic (right) poleward of $40^{\circ}$. Contours of average scaled potential vorticity from ERA-I in the vortex edge region $\left(1.4,1.6\right.$, and $\left.1.8 \times 10^{-4} \mathrm{~s}^{-1}\right)$ are overlaid in black. The months shown correspond to those with the largest magnitude $T_{\min }$ monthly CPADs. The temperature scales are the same as shown in Fig. 4, which differ for the Arctic and Antarctic and are not symmetric about 0 . The dark blue (red) extremes of the color bars indicate that the ERA-I (MERRA) average temperatures for the listed months within the five comparison periods tend to be greater than those for MERRA (ERA-I).

to 1 and one non-concentric case (28 February 1996) when MERRA and ERA-I have VTC close to 0.

We also use trajectory diagnostics to examine temperature histories of air parcels; these provide important information about the potential for polar processing. Here we use a trajectory code adapted from the Lagrangian Trajectory Diagnostic code described by Livesey et al. (2015), which advects parcels using fourth-order Runge-Kutta integration. The code uses linear interpolation to approximate winds and other fields at intermediate timesteps and to determine the values of these fields at parcel locations. The trajectories are calculated using the 6-hourly (00:00, 06:00, 12:00, and 18:00 UT) wind and temperature fields from MERRA and ERA-I. Our standard runs consist of isentropic 15-day forward and backward (30 days total) trajectories of parcels initialized at 00:00 UT on an equal-area grid. For this paper, we used 15 min timesteps for the Runge-Kutta integration and parcels initialized on the $490 \mathrm{~K}$ potential temperature surface configured on hemispheric equal-area grids from 40 to $90^{\circ} \mathrm{N}$ or -90 to $-40^{\circ} \mathrm{S}$ with $0.5 \times 0.5^{\circ}$ equatorial spacing (corresponding to $\sim 30000$ parcels). We examine parcels initialized in cold regions defined by $\mathrm{T} \leq 195 \mathrm{~K}$ (the approximate NAT threshold at $490 \mathrm{~K}$ ) and the amount of time these parcels spend below $195 \mathrm{~K}$ before and after the initialization date. From this subset of parcels, we calculate and compare distributions for total time spent below $195 \mathrm{~K}$ (TT195) and continuous time spent below $195 \mathrm{~K}$ (CT195) as described by Manney et al. (2003, 2005a).

\section{Results}

\subsection{Monthly comparison period average differences}

Figure 3 shows an example of the type of differences we calculate for most of the diagnostic intercomparisons (in this case $T_{\min }$ ) for $1979 / 80-2013 / 14$. The orange line showing the differences for 2012/2013 provides an example of the magnitude of differences in an individual recent year. Note that there are large day-to-day variations in differences and that the differences are largest in December 2012 and early January 2013, when the polar vortex was unusually disturbed prior to/during a major sudden stratospheric warming (SSW) with a vortex split (Coy and Pawson, 2015). The departure of the daily average differences (from 1979/80 to 2013/14; thick black line) from zero suggests that there exist persistent differences between the two reanalyses that dominate for much of the 34 years. Since these differences vary over the season, we define "monthly comparison period average differences" (monthly CPADs) between the data sets as the monthly means of the average daily differences over the comparison period years defined in Fig. 1. These quantities provide a compact means of summarizing the agreement between the data sets for a given month within a subset of years and of comparing the magnitude of differences between comparison periods for a particular diagnostic. We 


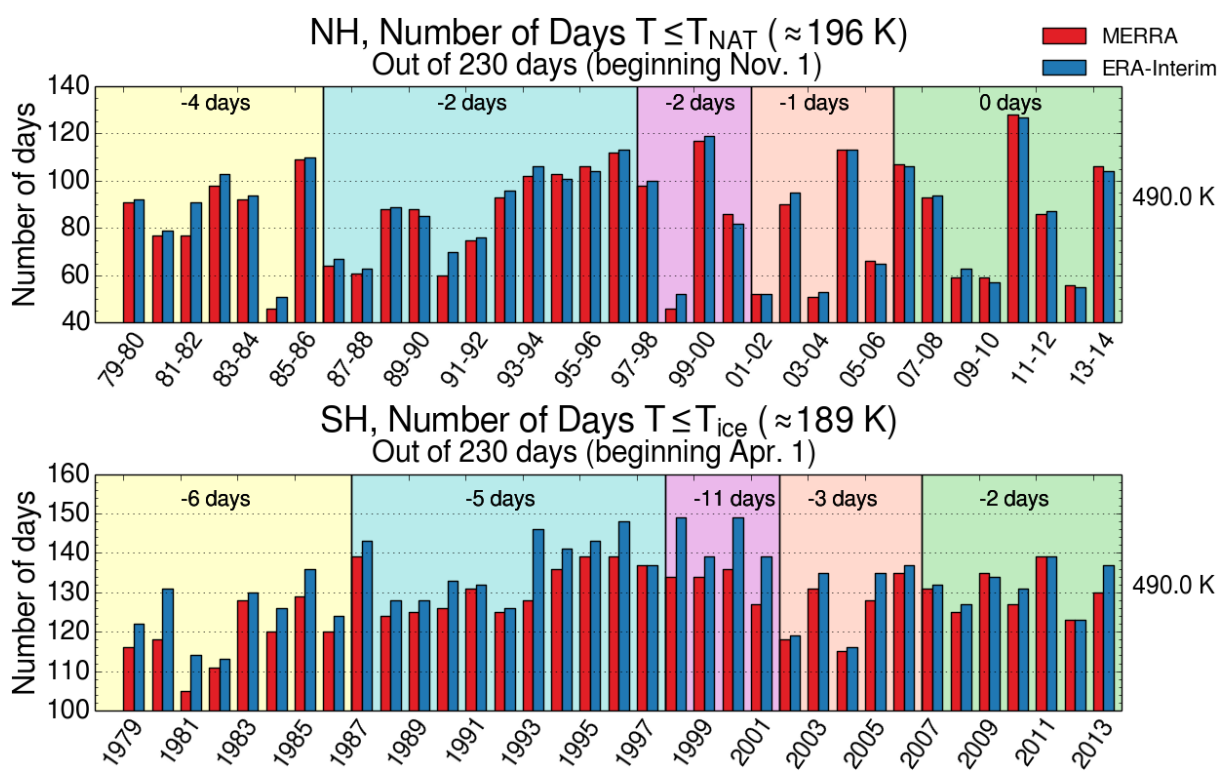

Figure 6. Number of days with Arctic (top) and Antarctic (bottom) winter minimum temperatures below NAT and ice PSC thresholds at $490 \mathrm{~K}$. Note that the $y$ axes do not start from zero and have different ranges for each hemisphere. The yellow, cyan, magenta, orange, and green colors shown behind the bars correspond to the colors of the comparison periods shown in Fig. 1, which represent 1979-1986, 1987-1997, 1998-2001, 2002-2006, and 2007-2013, respectively. The black numbers at the top of each colored region indicate the average differences (MERRA minus ERA-I) for the time period, rounded to the nearest day.

emphasize that monthly CPADs are meant to diagnose significant differences between the two data sets; they are not an assessment of the absolute accuracy of either. For the rest of this paper, we use the convention of subtracting ERA-I from MERRA (that is, MERRA minus ERA-I) to calculate the monthly comparison period average differences. Thus, differences in a diagnostic greater (less) than zero indicate that, on average, MERRA is greater (less) than ERA-I.

\subsection{Temperature diagnostic intercomparisons}

The seasonal progression of polar minimum temperatures provides an indication of when conditions favor the development of PSCs. The dependence of PSC formation on a temperature threshold implies that conclusions drawn from the $T_{\min }$ diagnostic are most sensitive to differences at the beginning and end of the season when minimum temperatures first drop below or rise above PSC thresholds. For the Arctic, these periods are typically around the beginning of December and mid-March, respectively, but large interannual variability and the common occurrence of mid-winter SSWs can result in much earlier or later threshold dates in individual years (Manney et al., 2005a, and references therein). In the Antarctic, the threshold periods tend to be in the first half of May and in mid-October. Figure 4 shows the monthly CPADs between MERRA and ERA-I at the $580 \mathrm{~K}$ level $(\sim 30 \mathrm{hPa}$, corresponding to an approximate $T_{\mathrm{NAT}}$ of $193 \mathrm{~K}$ ). For years preceding 2002, MERRA consistently has lower minimum temperatures than ERA-I. The Antarctic monthly CPADs in this period are particularly large, with differences between -5 and $-6 \mathrm{~K}$ in some months, in contrast to the largest differences in the Arctic, which are about $-1.4 \mathrm{~K}$. Differences in 1998-2001, after the introduction of the ATOVS instruments but before the introduction of the Aqua instruments, are significantly reduced over those prior to 1998. In both hemispheres, there is a distinct shift in agreement after the introduction of the Aqua instruments from 2002 onward (likely due to the vast increase in the number of observations included by assimilating AIRS data (see, e.g., McNally et al., 2006, and Rienecker et al., 2011). This is especially easy to see for the Antarctic, where the differences are reduced to values akin to those in the Arctic. In the Northern Hemisphere (NH), the shift marks the first period in which ERA-I minimum temperatures become consistently lower than those from MERRA. At lower levels down to about $460 \mathrm{~K}$ (not shown), the $T_{\min }$ monthly CPADs are smaller in magnitude (e.g., at $490 \mathrm{~K}$ they are between -0.4 and $0.7 \mathrm{~K}$ in the Arctic and -2 to $2 \mathrm{~K}$ in the Antarctic) and have different seasonal variations, with ERA-I having comparatively more months in the first three time periods with lower minimum temperatures.

To examine the global variation of temperature differences between MERRA and ERA-I, Fig. 5 shows maps of mean temperature differences (averaged over the time periods of interest from Fig. 1) for the months with the largest $T_{\min }$ monthly CPADs in Fig. 4. The maps for the Arctic, with the more symmetric color bar, clearly show that the regions where MERRA is colder tend to be mostly confined between 
$\pm 90^{\circ}$ longitude and poleward of $60^{\circ} \mathrm{N}$. This is a preferred direction for the polar vortex and cold region to be shifted off the pole in Arctic winters (e.g., Waugh and Randel, 1999). Outside of this area, ERA-I temperatures are, for the most part, lower than those from MERRA. In the Southern Hemisphere $(\mathrm{SH})$, the first three time periods show that the regions that are colder in MERRA are fairly symmetric poleward of the $60^{\circ} \mathrm{S}$ latitude circle. Examination of the mean temperature fields (not shown) for these periods suggests that larger differences are associated with lower temperatures. The maps for the following two time periods, from 2002 to 2013, demonstrate that the change seen in Fig. 4 reflects a large shift throughout the polar regions: the largest temperature differences during these periods are confined to relatively small regions, and overall the temperature differences lie between $\pm 0.4 \mathrm{~K}$ in both hemispheres. Simmons et al. (2014) show extratropical zonal-mean temperature differences between ERA-I and MERRA at $30 \mathrm{hPa}$ that indicate that the extratropics $\left( \pm 20-90^{\circ}\right.$ latitude) are colder in ERA-I than in MERRA for most of the reanalysis period. The results shown here are generally consistent with that finding but suggest that this result does not always hold true in the polar regions (above $60^{\circ} \mathrm{N}$ and below $60^{\circ} \mathrm{S}$ ) in winter/spring.

The number of days below PSC thresholds, a diagnostic derived from $T_{\min }$, for winters in the 1979-2013 period is shown at $490 \mathrm{~K}(\sim 56 \mathrm{hPa})$ for both hemispheres in Fig. 6 . We show days below $T_{\text {ice }}$, rather than $T_{\mathrm{NAT}}$, in the Antarctic because the periods with temperatures below $T_{\mathrm{NAT}}$ and $T_{\text {ice }}$ are much longer than the periods below these temperature thresholds in the Arctic, making the differences in the $\mathrm{SH}$ more apparent for the lower (i.e., more sensitive) ice threshold. This diagnostic indicates the approximate duration of the period with conditions conducive to polar processing. Overall, the number of cold days from ERA-I is greater than the number from MERRA in both hemispheres at this level. The Antarctic differences before 2002 are quite large, with some years showing ERA-I having over 10 more days with temperatures below the ice PSC threshold than MERRA. At levels up to $580 \mathrm{~K}$ (not shown), the situation in the Antarctic is opposite; that is, MERRA has significantly more days (sometimes between 20 and 30 days in years before 2002) with temperatures below the ice PSC threshold than ERA-I does. These results, along with those discussed above for $T_{\min }$, suggest that not only may the choice of data set have a large influence on analysis and modeling of polar processes in the Antarctic for years preceding 2002 but also effects may vary qualitatively and quantitatively in the vertical. In contrast to those for the Antarctic, the magnitudes of differences in the Arctic at higher levels up to $580 \mathrm{~K}$ are largely similar to those at $490 \mathrm{~K}$ but with MERRA having more cold days than ERAI.

Average values for the total area with temperatures below the NAT threshold at $580 \mathrm{~K}$ are displayed in Fig. 7. The Arctic maximum mean area is just above $3 \%$ of the hemisphere for ERA-I, while MERRA reaches nearly $4 \%$. In a similar

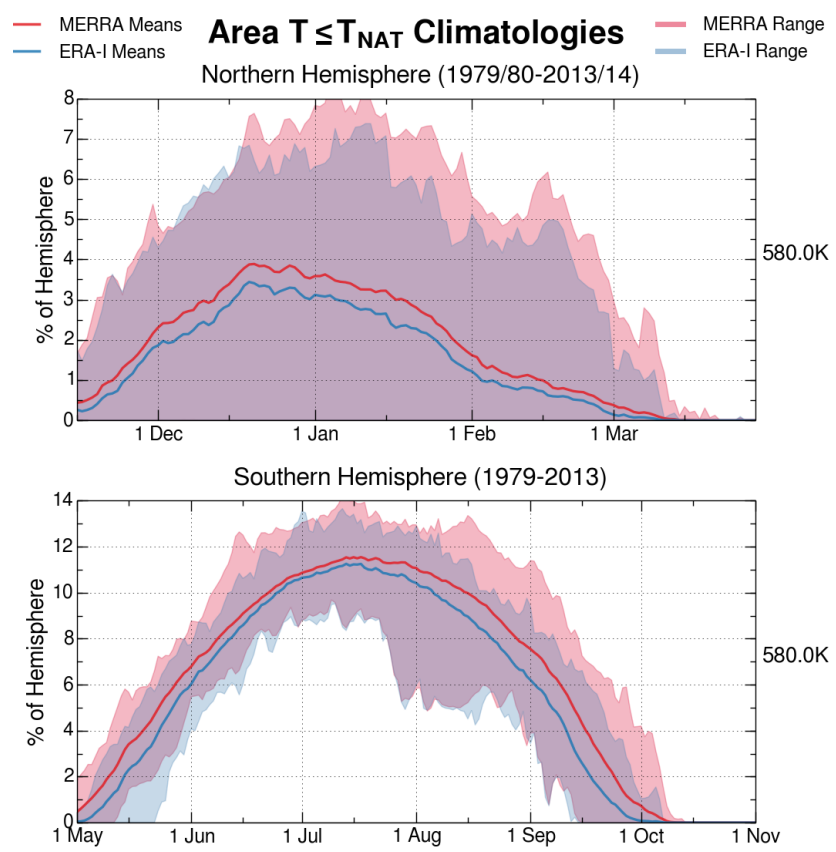

Figure 7. Mean values for $A_{\mathrm{NAT}}$ (thick red/blue lines), expressed as a percentage of a hemisphere, for Arctic (top) and Antarctic (bottom) winters at $580 \mathrm{~K}$ potential temperature. The blue (red) envelope shows the range of ERA-I (MERRA) values, with purple indicating where the ranges of the two reanalyses overlap.

fashion, the Antarctic maximum mean area is about $11 \%$ of the hemisphere for ERA-I while that for MERRA reaches nearly $12 \%$. Differences in these mean values between the reanalyses vary considerably with the season in both hemispheres. Figure 8 shows the corresponding monthly CPADs for $A_{\mathrm{NAT}}$. Here it is worth noting that the small differences in the last month of the season in each hemisphere are expected, as these include many days that have zero differences since minimum temperatures have risen above the NAT threshold in both reanalyses. Consistent with the $T_{\min }$ monthly CPADs, there is much closer agreement after the first three periods. The relatively frequent occurrence of warm Arctic winters after 1998 (e.g., Manney et al., 2005a) suggests that the third comparison period for the $\mathrm{NH}$ might be less easily compared with the second comparison period (which contained unusually cold Arctic winters (e.g., Pawson and Naujokat, 1999), but the marked decreases of the monthly CPADs in the SH still indicate a substantial effect due to changes in assimilated observations. In most cases the monthly CPADs are positive, indicating that MERRA tends to have larger cold regions than ERA-I at this level in both hemispheres. For levels below $580 \mathrm{~K}$, down into the upper troposphere/lower stratosphere region at $390 \mathrm{~K}$, MERRA still tends to have larger cold regions than ERA-I, but the conditions are different: the differences are much smaller in all periods, generally lying between -1 and $1 \%$ of a hemisphere in the Antarctic and -0.4 and $0.4 \%$ of a hemisphere in the Arctic. Figure 9 
Area $T \leq \mathrm{T}_{\mathrm{NAT}}$ Comparisons (@ $580 \mathrm{~K}$ )
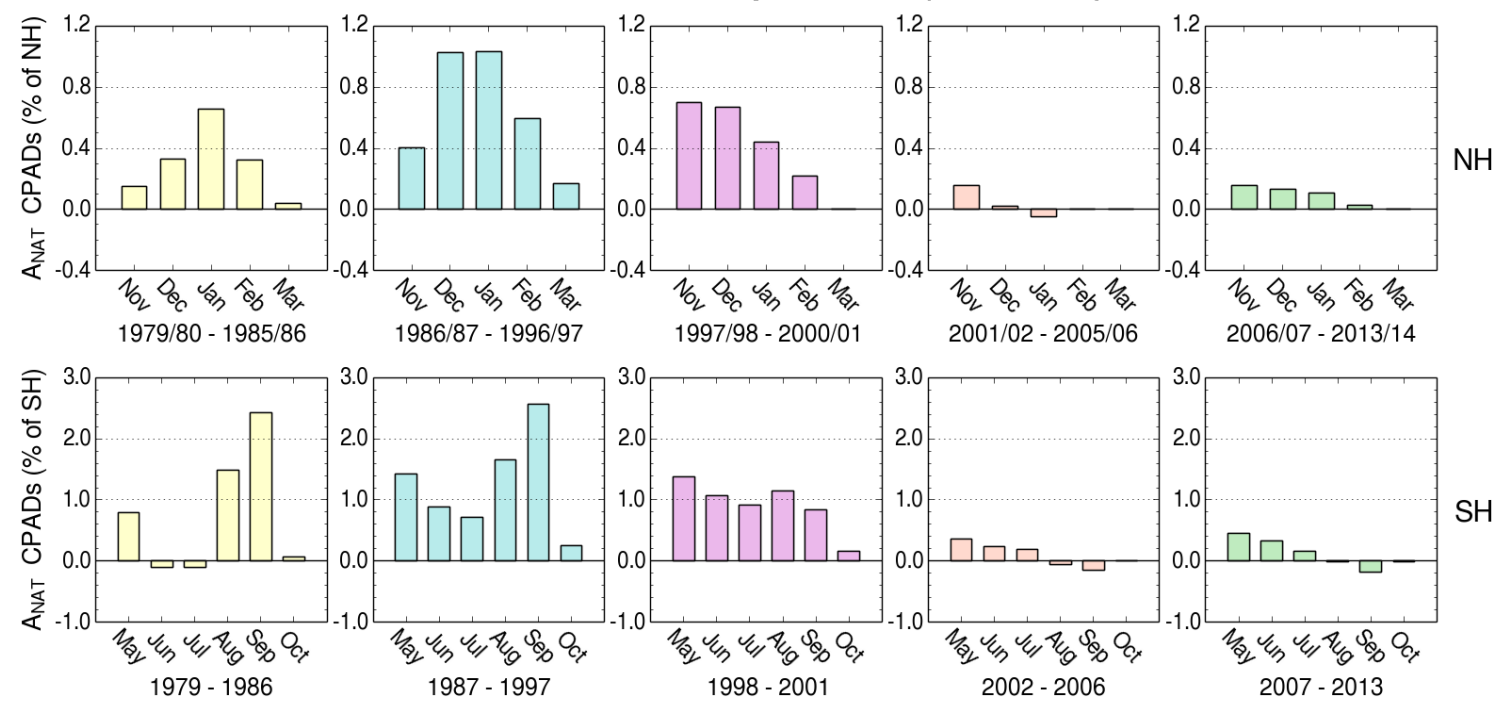

Figure 8. Monthly CPADs of $A_{\mathrm{NAT}}$ (in \% of a hemisphere) between MERRA and ERA-Interim at $580 \mathrm{~K}$ potential temperature for Arctic (top row) and Antarctic (bottom row) winters. The yellow, cyan, magenta, orange, and green colors used in the columns correspond to the colors of the comparison periods shown in Fig. 1, which represent 1979-1986, 1987-1997, 1998-2001, 2002-2006, and 2007-2013, respectively. The NH (SH) panels cover months from November to March (May to October). Note that the $A_{\mathrm{NAT}}(y$ axis) scales are different for each hemisphere.
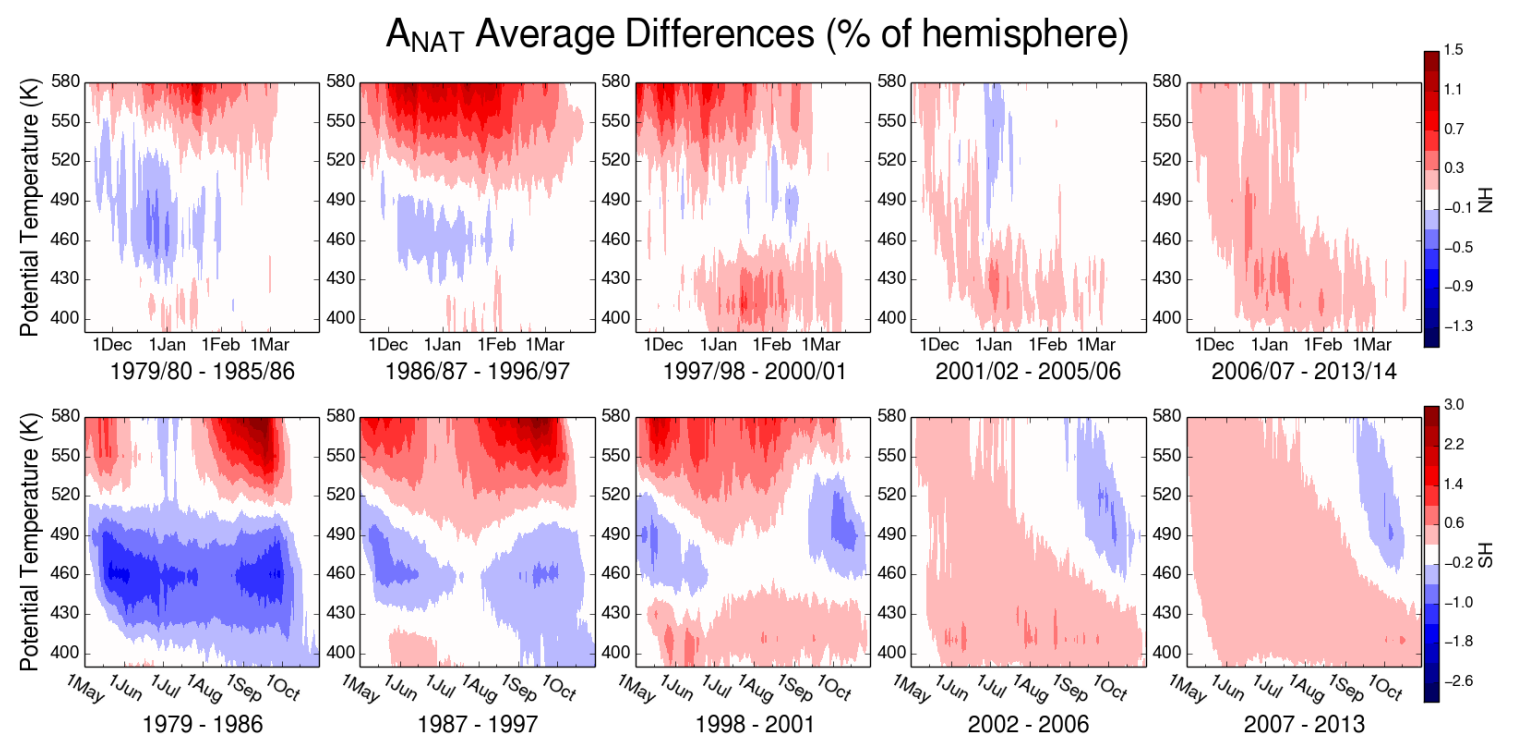

Figure 9. Differences in $A_{\mathrm{NAT}}$ (in \% of a hemisphere) between MERRA and ERA-I from 390 to $580 \mathrm{~K}$, averaged over the comparison periods of Fig. 1 for Arctic (top row) and Antarctic (bottom row) winters. The blue (red) colors indicate when and where ERA-I (MERRA) $A_{\text {NAT }}$ tends to be greater than MERRA (ERA-I) $A_{\text {NAT }}$.

demonstrates this behavior; it shows time series contour plots of the MERRA minus ERA-I $A_{\mathrm{NAT}}$ differences averaged over the comparison periods from Fig. 1. Although the differences are smaller at lower levels, the same convergence towards better agreement we see at $580 \mathrm{~K}$ is not always seen at levels below $520 \mathrm{~K}$, especially in the Arctic around 410 and $430 \mathrm{~K}$.

\subsection{Vortex diagnostic intercomparisons}

Maximum PV gradients indicate the strength of the polar vortex as a barrier to transport and mixing of air from lower latitudes with the cold vortex air where chlorine activation takes place (e.g., Manney et al., 2011). The seasonal evolution and mean values of MPVGs at $490 \mathrm{~K}$ are shown in 


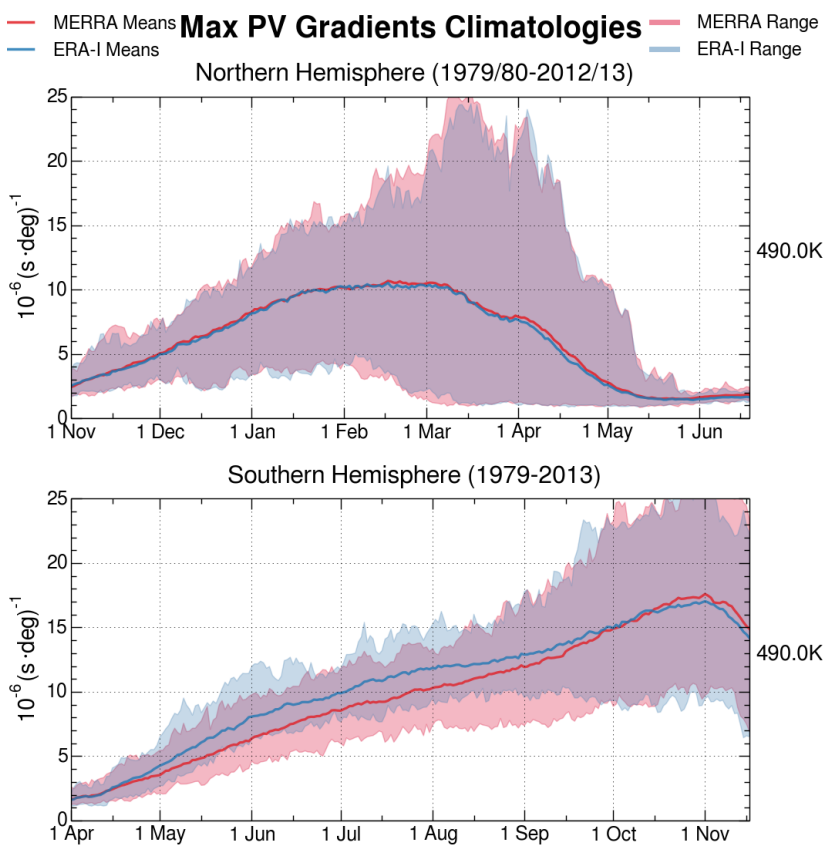

Figure 10. Mean values for maximum PV gradients (thick red/blue lines) for Arctic (top) and Antarctic (bottom) winters at $490 \mathrm{~K}$ potential temperature. The blue (red) envelope shows the range of ERA-I (MERRA) values, with purple indicating where the ranges of the two reanalyses overlap.

Fig. 10. The primary difference between the hemispheres is seen in the average values: the Arctic maximum gradients tend to level off at around $10^{-5} \mathrm{~s}^{-1} \mathrm{deg}^{-1}$ early in the season, while the Antarctic maximum gradients steadily increase up to approximately $1.7 \times 10^{-5} \mathrm{~s}^{-1} \mathrm{deg}^{-1}$ near the end of the season. The MPVG monthly CPADs are shown in Fig. 11. Note that the scaling of the values is $10^{-6} \mathrm{~s}^{-1} \mathrm{deg}^{-1}$. This means that a difference of 1 would be one-fifth the height of a grid box from Fig. 10. As such, the monthly CPADs are overall quite small, but the monthly and comparison period variations still provide useful information. For instance, the greater MERRA MPVGs in the months when the vortex usually weakens (March or April in the Arctic, November in the Antarctic) suggest that the polar vortices as represented by ERA-I tend to weaken earlier than those in MERRA. Furthermore, a shift in agreement contemporaneous with those seen in Figs. 4 and 8 is also present. In this case, however, the monthly CPADs increase considerably for the $\mathrm{NH}$ rather than decrease. This behavior, with agreement in the $\mathrm{SH}(\mathrm{NH})$ improving (degrading) slightly, is also seen at other vertical levels between 460 and $580 \mathrm{~K}$ (not shown).

Similar to $A_{\mathrm{PSC}}$, the sunlit area of the vortex provides an approximate quantitative measure of the area on a given vertical level where chlorine-catalyzed ozone destruction can take place. Different sunlit area diagnostics have been used in detailed polar processing studies to establish correlations between the coverage (e.g., Feng et al., 2007) and duration (e.g., Rex et al., 1999; Livesey et al., 2015) of sunlight and ozone loss; these diagnostics are usually somewhat computationally intensive, whereas the diagnostic used here (described in Sect. 2.4 above) is simple enough to compute for multiple long-term data sets. Figure 12 shows time series averages and ranges of the sunlit vortex area diagnostic as a percentage of a hemisphere at $490 \mathrm{~K}$. The seasonal variations of the sunlit vortex are very similar in both data sets. Small differences can, however, be seen: the ERA-I Arctic polar vortex tends to be filled with slightly more sunlight than the MERRA vortex, while in the Antarctic the differences change over the season. Consistent with this, the sunlit vortex area monthly CPADs in Fig. 13 show predominantly negative values in the Arctic (in agreement with Fig. 12, which showed ERA-I values greater than those from MERRA) and differences that change sign in the Antarctic. Like the NH MPVG monthly CPADs, the NH sunlit vortex area monthly CPADs increase to a maximum by the last time period (2007-2013) of Fig. 1. The overall maximum monthly CPADs occur in November and February of this final time period, both months when a substantial portion of the vortex is typically in darkness and varying sunlight may affect chlorine activation whenever temperatures are low enough for PSC formation. In contrast to those for the $\mathrm{NH}$, the SH monthly CPADs improve slightly over the reanalysis period. Differences of the small magnitude shown here are unlikely to have large effects on polar processing in either hemisphere, especially in the Antarctic, where the vortex is larger, colder, and less variable from year to year than in the Arctic. The vertical structure of the sunlit vortex area differences (not shown) is complicated, but for recent years the ERA-I NH polar vortex tends to have a larger area in sunlight than that in MERRA at levels between 460 and $550 \mathrm{~K}$, while the opposite is true for the SH. The differences in sunlit vortex areas shown here primarily arise from corresponding differences between MERRA and ERA-I in the total vortex area $\left(A_{\text {vort }}\right.$, not shown). However, small discrepancies between the monthly CPADs of sunlit and the total vortex area indicate that differing vortex positions in the two reanalyses also affect the monthly CPADs slightly.

The winter mean vortex fraction of cold air diagnostic helps to identify years with conditions favorable for PSC formation and ozone loss. In the Arctic, years with low values of $V_{\mathrm{PSC}} / V_{\mathrm{vort}}$ correspond to the winters with very short cold periods usually associated with a disturbed vortex and midwinter SSWs. Because of its relationship to column ozone loss, $V_{\mathrm{PSC}}$ has been used extensively in climatological ozone loss studies (e.g., Rex et al., 2004, 2006; Tilmes et al., 2006; Pommereau et al., 2013; Rieder and Polvani, 2013). $V_{\text {vort }}$ as a stand-alone diagnostic is much less common; however, the volume of air within the vortex is an indicator of the absolute size of the region over which chemical ozone loss can occur. Figures 14 and 15 show winter mean $V_{\mathrm{PSC}} / V_{\text {vort }}$ for the Arctic and Antarctic, respectively, along with the corresponding winter mean $V_{\mathrm{PSC}}$ and $V_{\text {vort }}$ values separately. In 


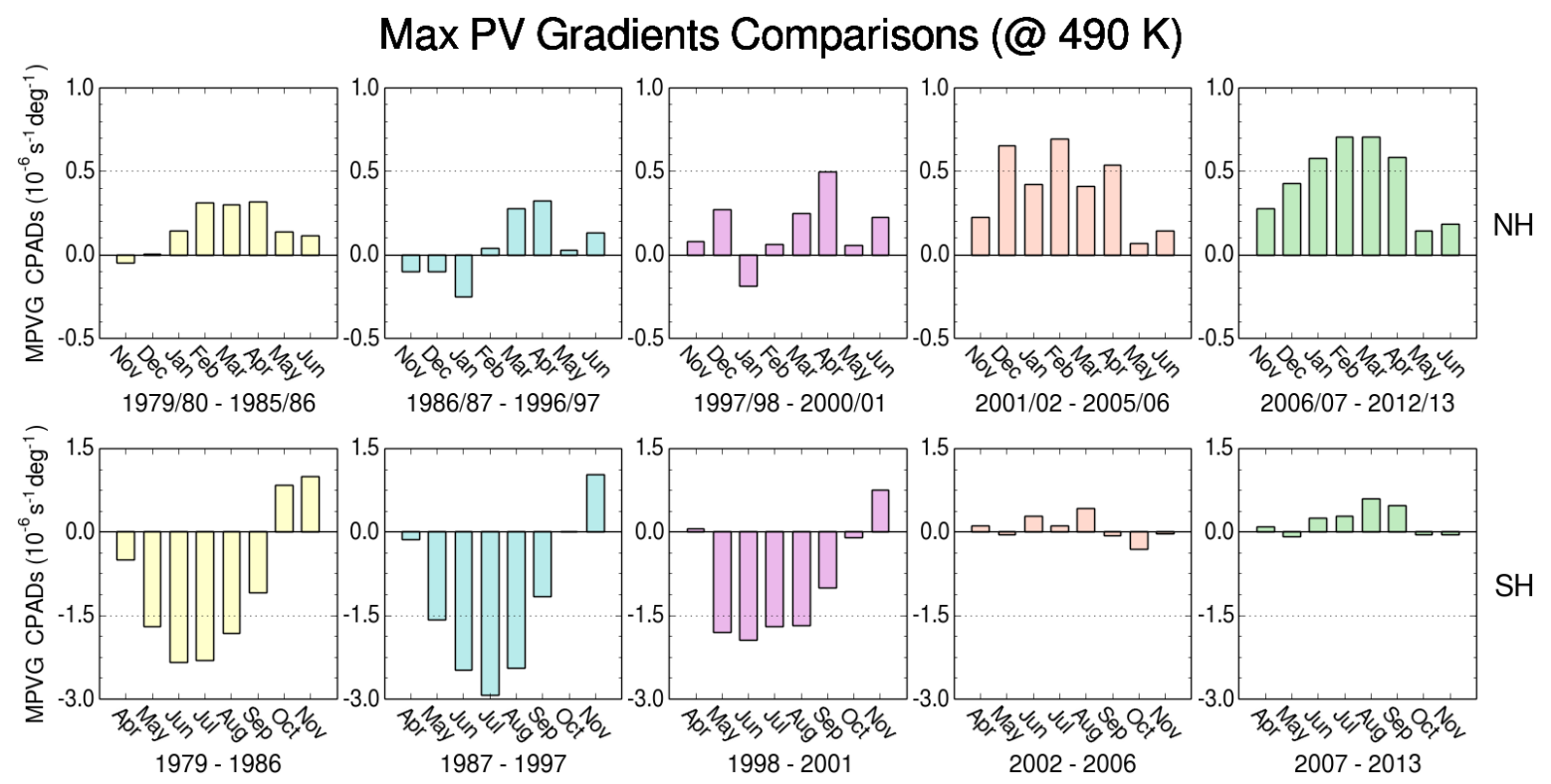

Figure 11. Monthly CPADs of maximum potential vorticity gradients (MPVGs) between MERRA and ERA-Interim at $490 \mathrm{~K}$ potential temperature for Arctic (top row) and Antarctic (bottom row) winters. The yellow, cyan, magenta, orange, and green colors used in the columns correspond to the colors of the comparison periods shown in Fig. 1, which represent 1979-1986, 1987-1997, 1998-2001, 20022006, and 2007-2013, respectively. The NH (SH) panels cover months from November to June (April to November). Note that the MPVG ( $y$ axis) scales are different for each hemisphere.
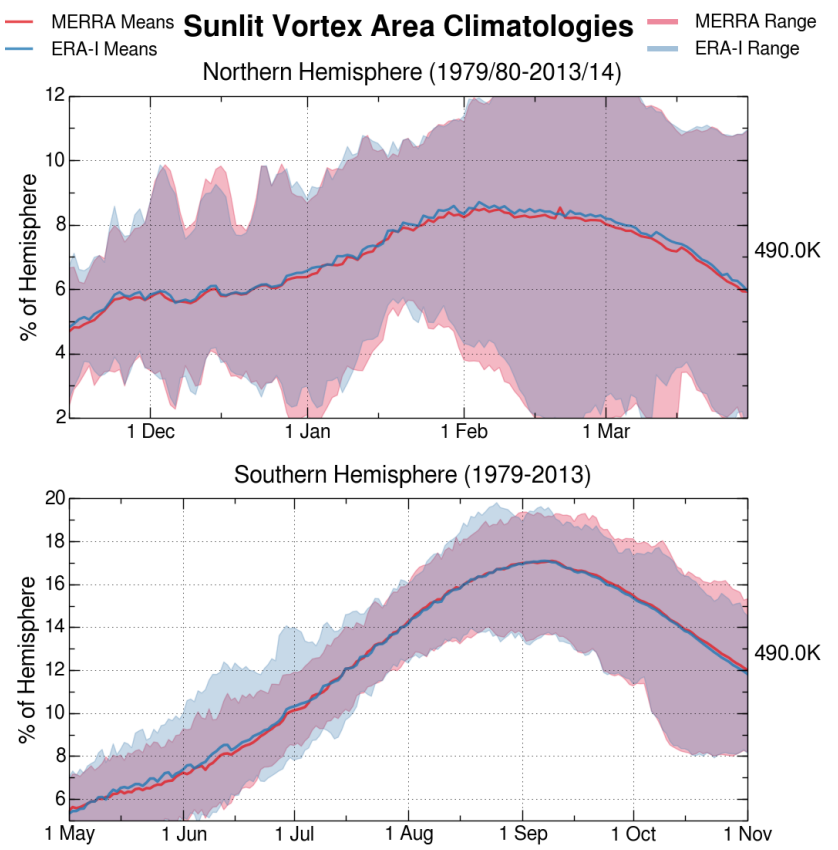

Figure 12. Mean values for the sunlit area of the polar vortex (thick red/blue lines), expressed as percentages of a hemisphere, for Arctic (top) and Antarctic (bottom) winters at $490 \mathrm{~K}$ potential temperature. The blue (red) envelope shows the range of ERA-I (MERRA) values, with purple indicating where the ranges of the two reanalyses overlap. general, MERRA tends to have a larger volume of cold air in both hemispheres, consistent with the larger $A_{\text {NAT }}$ monthly CPADs shown in Fig. 8 and the average differences shown in Fig. 9. The only major exceptions are the years from 1979 to 1987 in the Antarctic, where ERA-I $V_{\text {ice }}$ is a bit larger than that in MERRA. The lack of improvement in agreement for $V_{\mathrm{PSC}}$ follows directly from the prior discussion of $A_{\mathrm{NAT}}$; since the agreement of $A_{\mathrm{NAT}}$ between MERRA and ERA-I below $520 \mathrm{~K}$ generally does not improve much over time, neither does that of $V_{\mathrm{PSC}}$. Consistent with the differences discussed in the sunlit vortex area (Figs. 12 and 13), MERRA's $V_{\text {vort }}$ values are very similar to those of ERAI. Thus, on average, the differences in $V_{\mathrm{PSC}} / V_{\text {vort }}$ between MERRA and ERA-I reflect the differences seen in $V_{\mathrm{PSC}}$. Exceptions to this are in 2007-2013 in the NH, when slightly smaller MERRA $V_{\text {vort }}$ values emphasize the $\sim 0.01$ larger $V_{\mathrm{PSC}} / V_{\text {vort }}$ values seen in MERRA, and in 1979-1987 in the $\mathrm{SH}$, when the $\sim 0.02$ larger ERA-I $V_{\mathrm{PSC}} / V_{\text {vort }}$ values represent larger cold fractions of smaller vortices. This analysis demonstrates several caveats for comparisons of diagnostics that rely on vertical integration, time averages, or combinations of both. Their dependence on time and/or altitude can lead to cancellations and smoothing when integrated and/or time averaged, making comparisons of the final results difficult to interpret since agreement (or lack thereof) can come about for the wrong reasons. In this case, the agreement of winter mean $V_{\mathrm{PSC}}, V_{\mathrm{vort}}$, and $V_{\mathrm{PSC}} / V_{\text {vort }}$ between the reanalyses was affected by the representation of several conditions. Because the differences between MERRA and ERA-I 
Sunlit Vortex Area Comparisons (@ 490 K)
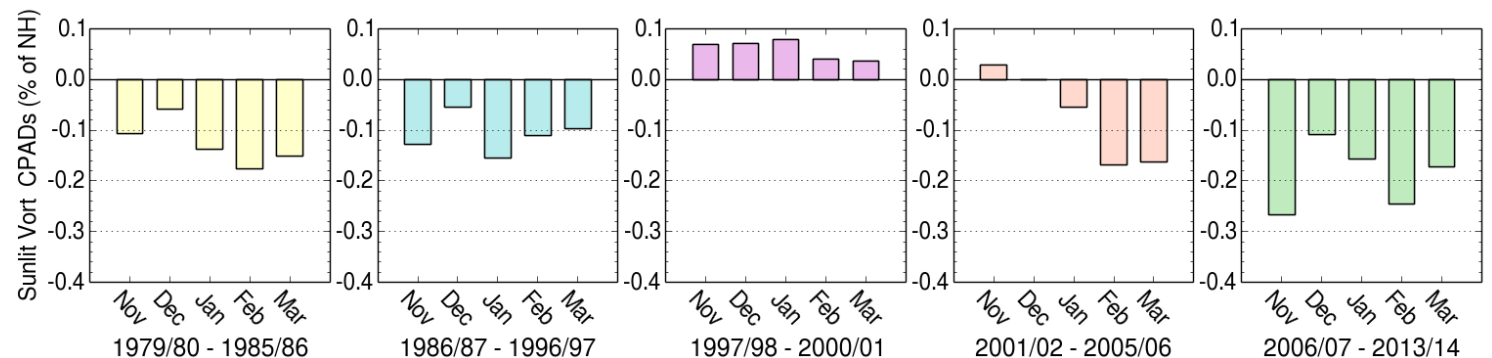

$\mathrm{NH}$

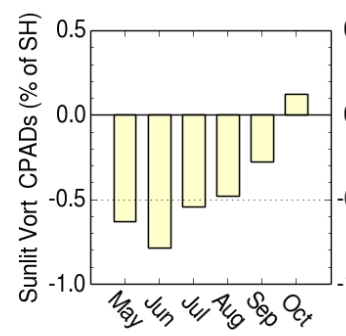

1979 - 1986

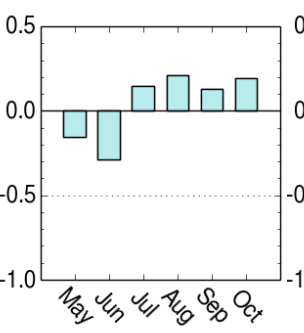

1987 - 1997

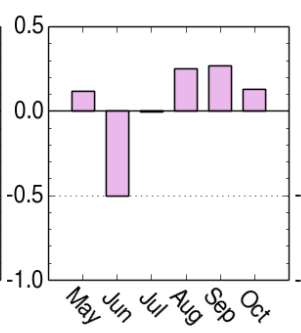

1998 - 2001

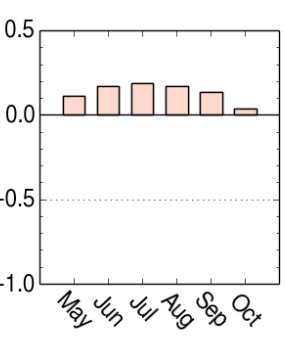

2002 - 2006

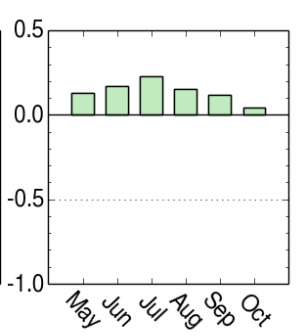

$2007-2013$

Figure 13. Monthly CPADs in sunlit vortex area between MERRA and ERA-Interim at $490 \mathrm{~K}$ potential temperature for Arctic (top) and Antarctic (bottom) winters. The yellow, cyan, magenta, orange, and green colors used in the columns correspond to the colors of the comparison periods shown in Fig. 1, which represent 1979-1986, 1987-1997, 1998-2001, 2002-2006, and 2007-2013, respectively. The NH (SH) panels cover months from November to March (May to October). Note that the sunlit area ( $y$ axis) scales are different for each hemisphere.

in $A_{\mathrm{PSC}}$ and $A_{\text {vort }}$ are not uniform in time and altitude (see Fig. 9), better agreement at some levels does not necessarily correlate with higher confidence in our knowledge of $V_{\mathrm{PSC}}$ and consequently $V_{\mathrm{PSC}} / V_{\text {vort }}$. This suggests that these diagnostics function better as qualitative measures and argues for considerable caution in interpretation of their time variations or trends.

The concentricity of the vortex with regions of air with $T \leq T_{\text {NAT }}$ (VTC) has not been widely used in polar processing studies. However, Mann et al. (2002), using a concentricity diagnostic different from that defined here, found that different values led to dramatically different patterns of denitrification in model simulations of NAT particle growth and evaporation, because differences in the position of the cold region relative to the strong winds bounding the vortex can result in large differences in the amount of time air spends in cold regions of comparable size (Manney et al., 2003). Using idealized model simulations with a constant vortex field and cold regions ranging from highly concentric to non-concentric, Mann et al. (2002) showed that concentricity affected denitrification independent of any variations in the vortex itself. Since our concentricity calculations require both the polar vortex and a cold region to be defined, intercomparisons of the resulting discontinuous time series can be difficult to interpret. Therefore, we present this diagnostic as occurrence frequencies of the range of VTC values, normalized by the total number of days on which VTC was calculated for each reanalysis. Figure 16 shows the results at the $490 \mathrm{~K}$ level. The total number of days shown corresponds to the number of days with a valid VTC value summed over the years from the comparison time periods defined in Fig. 1 and used in the monthly CPAD plots. As evidenced by the small regions of non-overlapping colors, in most cases the ERA-I vortices spend more time at higher concentricity values (within the 0.8 to 1.0 range) in both hemispheres. Consistent with the number of days below PSC thresholds shown in Fig. 6, ERA-I also tends to have more valid VTC days than MERRA in both hemispheres. The detailed implications of differences in concentricity are difficult to assess, but the results of Mann et al. (2002) and Manney et al. (2003) suggest that greater concentricity in ERA-I could lead model runs driven by that reanalysis to simulate longer-lasting PSCs, greater denitrification, and enhanced chlorine activation.

\subsection{Trajectory diagnostic intercomparisons}

Temperature histories along air parcel trajectories provide further information about polar processing potential beyond what can be obtained from the simple diagnostics described above. For these intercomparisons, we use isentropic trajectory calculations on the $490 \mathrm{~K}$ surface. As discussed by Manney et al. (2003), although neglecting cross-isentropic motion would not be suitable for detailed polar processing studies, this simplification allows us to efficiently run and analyze a large number of parcels for extensive intercomparisons. Following Manney et al. (2003, 2005a), we consider only the parcels that are initialized in regions with temperatures less than $195 \mathrm{~K}$. With this initial filter, we examine the total and continuous amounts of time that these parcels spend at 


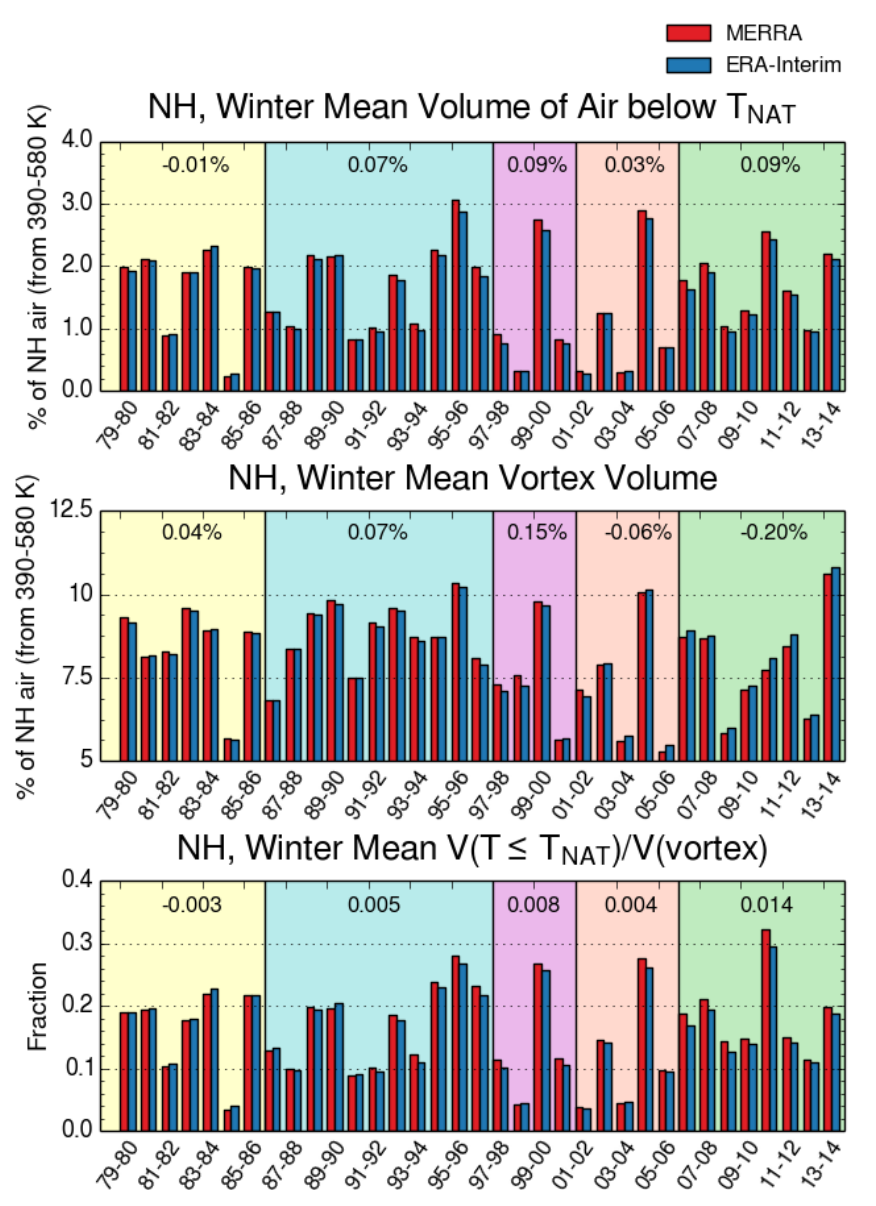

Figure 14. Arctic winter mean $V_{\mathrm{PSC}}$ (top), $V_{\text {vort }}$ (center), and $V_{\mathrm{PSC}}$ expressed as a fraction of vortex volume (bottom). Note that the $y$ axis for winter mean $V_{\text {vort }}$ does not start from zero. The yellow, cyan, magenta, orange, and green colors shown behind the bars correspond to the colors of the comparison periods shown in Fig. 1, which represent 1979-1986, 1987-1997, 1998-2001, 20022006, and 2007-2013, respectively. The black numbers at the top of each colored region indicate the average differences (MERRA minus ERA-I) for the time period.

temperatures below $195 \mathrm{~K}$ (TT195 and CT195, respectively) before and after the initialization date and the mean temperature of the parcels over the full run. The TT195 diagnostic captures the total exposure of an air mass to temperatures low enough for PSC formation and thus acts as a proxy for cumulative chlorine activation; CT195 better represents the potential lifetime of a PSC and is thus more directly relevant for denitrification, since sufficiently long continuous time at low temperatures allows PSC particles to grow to sizes large enough for sedimentation to occur (Manney et al., 2003, 2005a). Here we show trajectory calculations initialized on 10 January 1996 and 24 January 2011 for the NH and 17 September 1988, 13 September 2002, and 25 May 2011 for the SH. These dates have been chosen to span a range of conditions representative of the interannual variabil-

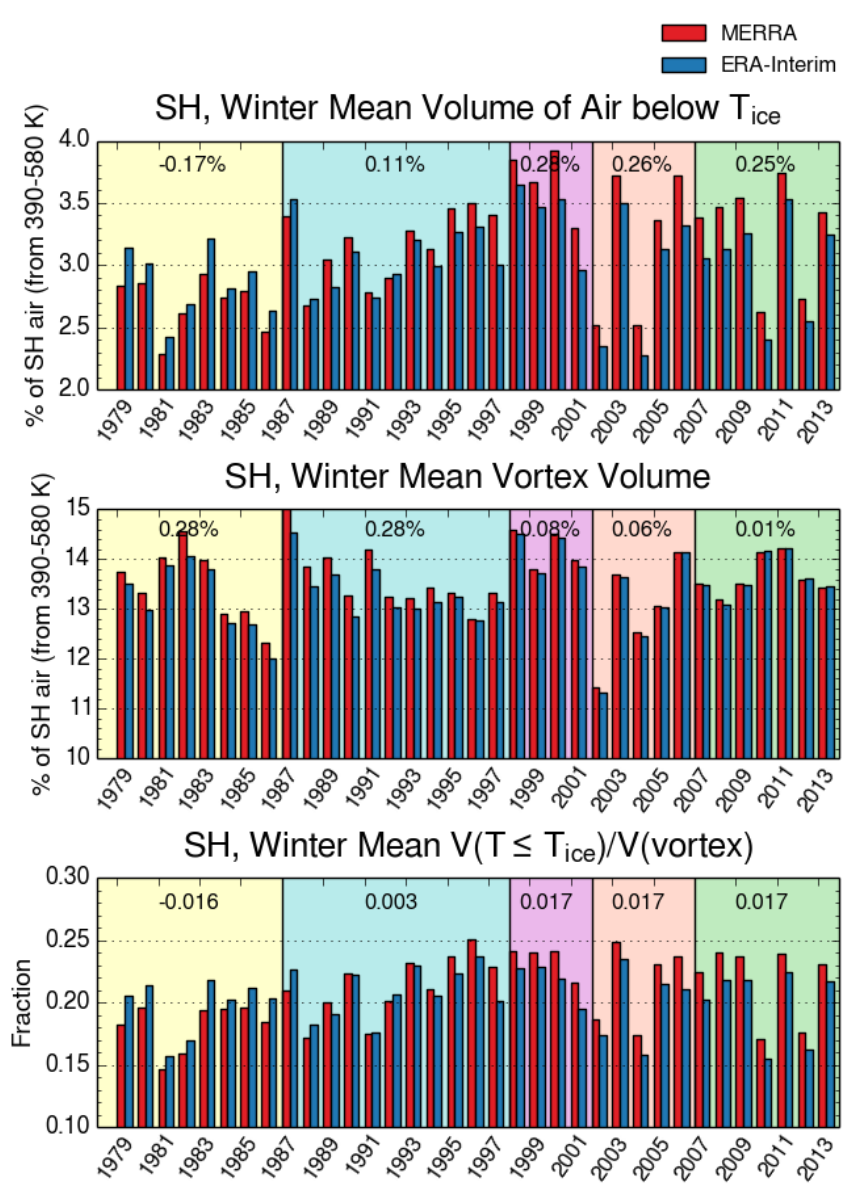

Figure 15. As in Fig. 14 but for the Antarctic. Also note that, here, none of the $y$ axes start from zero.

ity in both hemispheres and in some cases to compare with previous studies using the same diagnostics. Several other cases have been investigated for each hemisphere; the results shown here are representative.

Figure 17 summarizes the trajectory diagnostics for the NH. Overall, the parcel histograms for TT195 and CT195 are very similar between MERRA and ERA-I, with consistent distributions, peaks, and average values. The number of parcels included in the calculations indicate that MERRA has slightly larger regions of cold air, but the average values of the distributions only differ by approximately 0.05 days $(\sim 1.2 \mathrm{~h})$ for TT195 and 0.5 days $(\sim 12 \mathrm{~h})$ for CT195. Where there are small differences, they are consistent with minor spatial differences in maps of the parcels (not shown), which are also otherwise very similar. In investigating other $\mathrm{NH}$ winter initialization dates, we found that all agreed well (similar to the examples shown here) in each diagnostic for years as early as 1981 and as recent as 2013. The SH cases shown in Fig. 18 present a different picture. In particular, the mean parcel temperature plots reveal a significant improvement in agreement between MERRA and ERA-I over time. The 16 September 1988 case shows that MERRA parcels are 


\section{Relative Frequencies of Vortex \& Cold Region Concentricities @ 490K}

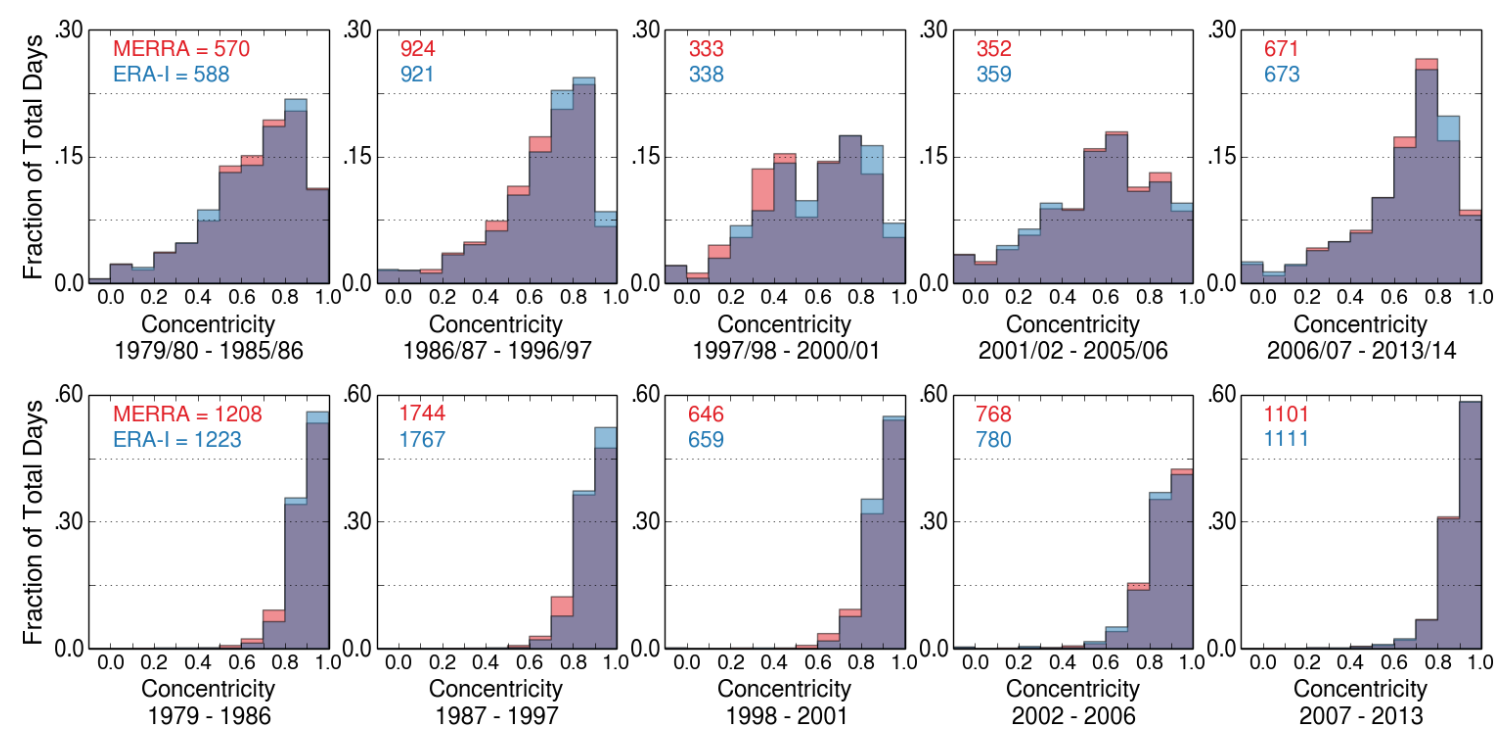

Figure 16. Concentricity of the polar vortex and regions with $T \leq T_{\mathrm{NAT}}$ at $490 \mathrm{~K}$ potential temperature expressed as relative frequencies of the total number of days with a valid concentricity value (red and blue numbers) from the time periods of Fig. 1 for Arctic (top) and Antarctic (bottom) winters. The blue (red) regions correspond to the distributions from ERA-I (MERRA), with purple indicating where the distributions of the two reanalyses overlap.

consistently warmer, with temperatures roughly $1 \mathrm{~K}$ greater than those in ERA-I. The 13 September 2002 case also shows that MERRA parcels are noticeably warmer but to a lesser extent than in 1988. Although we highlight a different part of the SH winter season for 2011, there is a lack of a discernible temperature differences in comparison to the two previous dates, in agreement with the results from Figs. 4 and 5, which showed that temperature differences between MERRA and ERA-I are smallest from 2002 to 2013. Therefore, we consider the 25 May 2011 initialization date to be representative. The TT195 and CT195 histograms also reflect this evolution in the differences over the years, with the parcels on average spending fewer days below $195 \mathrm{~K}$ for MERRA than for ERA-I when the mean temperature of the MERRA parcels is higher.

The above results suggest two things. For the NH, isentropic trajectory runs initialized with MERRA or ERA-I should provide very similar results in the lower stratosphere, even for early years, thus lending confidence that transport calculations using winds from these two reanalyses should give comparable outcomes. The same cannot be said for early years in the SH, where many fewer observations were available in the 1980s and 1990s, allowing differences in the models and DAS to dominate the data constraints. This resulted in systematic differences in temperature histories that are consistent with the large monthly CPADs seen in direct temperature diagnostics (e.g., Figs. 4-9). Overall, the agreement of the trajectory diagnostics from MERRA and ERA-I in both hemispheres is much better than that from older analyses: in previous intercomparison studies, Manney et al. (2003, 2005a) found very large differences in trajectory runs driven by fields from earlier analyses/reanalyses. Discrepancies in $465 \mathrm{~K}$ trajectories for average TT195 were as large in magnitude as 5 days for the $\mathrm{NH}$ and 7 days for the SH, with discrepancies in average CT195 in both hemispheres up to 2.5 days. For 10 January 1996 (shown here in Fig. 17), the time series of average parcel histories calculated by Manney et al. (2003) showed differences as large as $10 \mathrm{~K}$ on some days; in addition, the five analyses compared in that study showed qualitatively very different distributions of TT195 and CT195. Large qualitative differences were also seen between the analyses in September 2002 (Manney et al., 2005a) in contrast to the small differences and good qualitative agreement seen here in Fig. 18 (middle panels). The improvements in the agreement between MERRA and ERAI over that between earlier analyses, which largely ingested the same data, demonstrate the degree of improvement in the models and DAS techniques over the past decade.

\section{Discussion and Conclusions}

We have presented comparisons of stratospheric polar processing diagnostics derived from the MERRA and ERAInterim reanalyses for Arctic and Antarctic winters from 1979 to 2013. By using temperature, vortex, and trajectory diagnostics, we have comprehensively explored the major aspects of the dynamical fields that chemical destruction of polar ozone in the lower stratosphere is sensitive to. In addition, we have characterized how agreement between the 

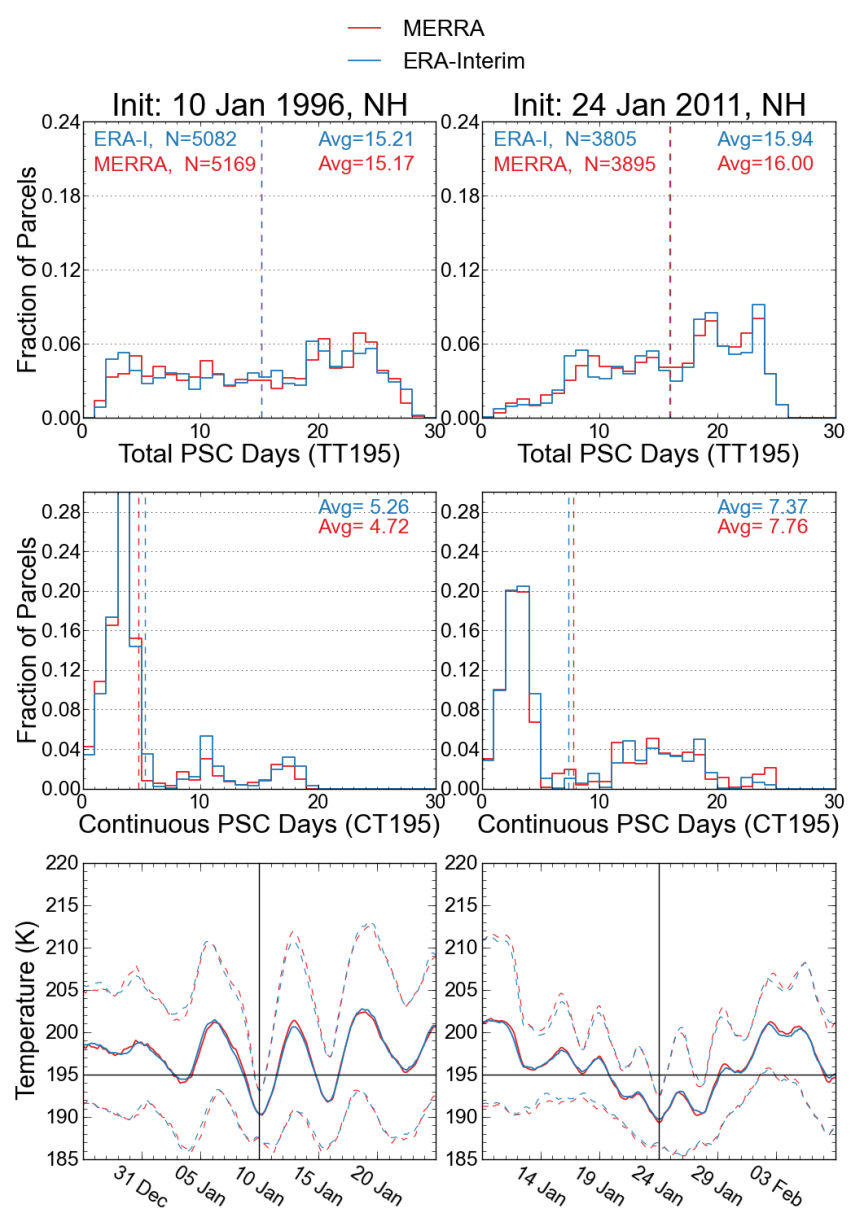

Figure 17. Temperature histories along air parcel trajectories at $490 \mathrm{~K}(\sim 56 \mathrm{hPa})$. Both of the columns are from Arctic winters. The first and second rows are histograms of parcels that spent total and continuous time in temperatures below $195 \mathrm{~K}$ (see text). The dashed vertical lines show the averages of TT195 and CT195 for each of the reanalyses. The last row is the mean temperature of the parcels initialized in the cold regions for the full 30-day (15-day forward/backward) trajectory runs; the black vertical line indicates the initialization date, while the black horizontal line marks $195 \mathrm{~K}$. The dashed red and blue curves show one standard deviation range.

two reanalyses evolved over the 1979-2013 period as assimilated observations changed. To do this, we compared the temperature and vortex diagnostics during five time periods bounded by large changes in the data sets that were assimilated. Most of the comparisons are shown using calculations of monthly comparison period average differences (monthly CPADs), which are monthly means of the daily differences between MERRA and ERA-I averaged over the aforementioned time periods. Our primary conclusions are as follows.

- Comparisons of temperature diagnostics derived from MERRA and ERA-I show a major shift towards better agreement in years after 2001, especially at levels above about $490 \mathrm{~K}$. At $580 \mathrm{~K}$ (around $30 \mathrm{hPa}$ ), ERA-I tends to have more days with lower temperatures, whereas MERRA tends to have larger regions of cold air. These results are consistent between the hemispheres.

- The comparisons of winter mean $V_{\mathrm{PSC}}$ have a complex dependence on time and altitude as evidenced by the $A_{\text {NAT }}$ monthly CPADs. The shift towards better agreement (in years after 2001) in both hemispheres for $A_{\text {NAT }}$ above $490 \mathrm{~K}$ was not enough to make the comparisons of winter mean $V_{\mathrm{PSC}}$ agree better.

- Comparisons based on differences of winter mean $V_{\text {PSC }} / V_{\text {vort }}$ can be complicated because of the dependence on vertical integrations and time averaging, and thus $V_{\mathrm{PSC}}$ and $V_{\text {vort }}$ individually. Since MERRA tends to have larger regions of cold air (larger $V_{\text {PSC }}$ ) than ERA-I and similarly or smaller-sized vortices in recent periods, MERRA also has larger vortex fractions of cold air in years beyond $\sim 1992$.

- The vortex diagnostic comparisons are more complicated than those of the temperature diagnostics. In many cases the monthly CPADs do not decrease in magnitude; some even increase over the 1979-2013 time period, especially in the Arctic. These differences, however, tend to be small in magnitude. (e.g., approximately $\sim 0.5 \times 10^{-6} \mathrm{~s}^{-1} \mathrm{deg}^{-1}$ for the maximum PV gradients and $\sim 0.2 \%$ of a hemisphere for sunlit vortex area in both hemispheres from 2002 to 2013).

- Isentropic trajectory runs driven by MERRA and ERAI give very similar results overall. We found that in the Northern Hemisphere the trajectory diagnostics agree very well across most of the years, while in the Southern Hemisphere the agreement improves significantly over time.

Overall, we found that agreement between MERRA and ERA-I is better in the Arctic than in the Antarctic for nearly all of the diagnostics, especially before approximately 2002 . The monthly CPADs in the Southern Hemisphere show large differences in the first three comparison periods (19791986, 1987-1997, and 1998-2001) before the introduction of ATOVS data in 1998 (and subsequent introduction of Aqua data in 2002) but evolve over time to approach the level of agreement found in the Northern Hemisphere. Consistent behavior was also seen in our calculations of temperature histories from air parcel trajectories, in which agreement of mean parcel temperatures and distributions of the time spent below PSC formation thresholds improved substantially as more observations were introduced into the DAS. Nevertheless, even the relatively poor agreement between MERRA and ERA-I in the Southern Hemisphere during the earlier periods with sparse data is still considerably better than that between analyses and reanalyses available a decade ago. Furthermore, 
- MERRA

- ERA-Interim
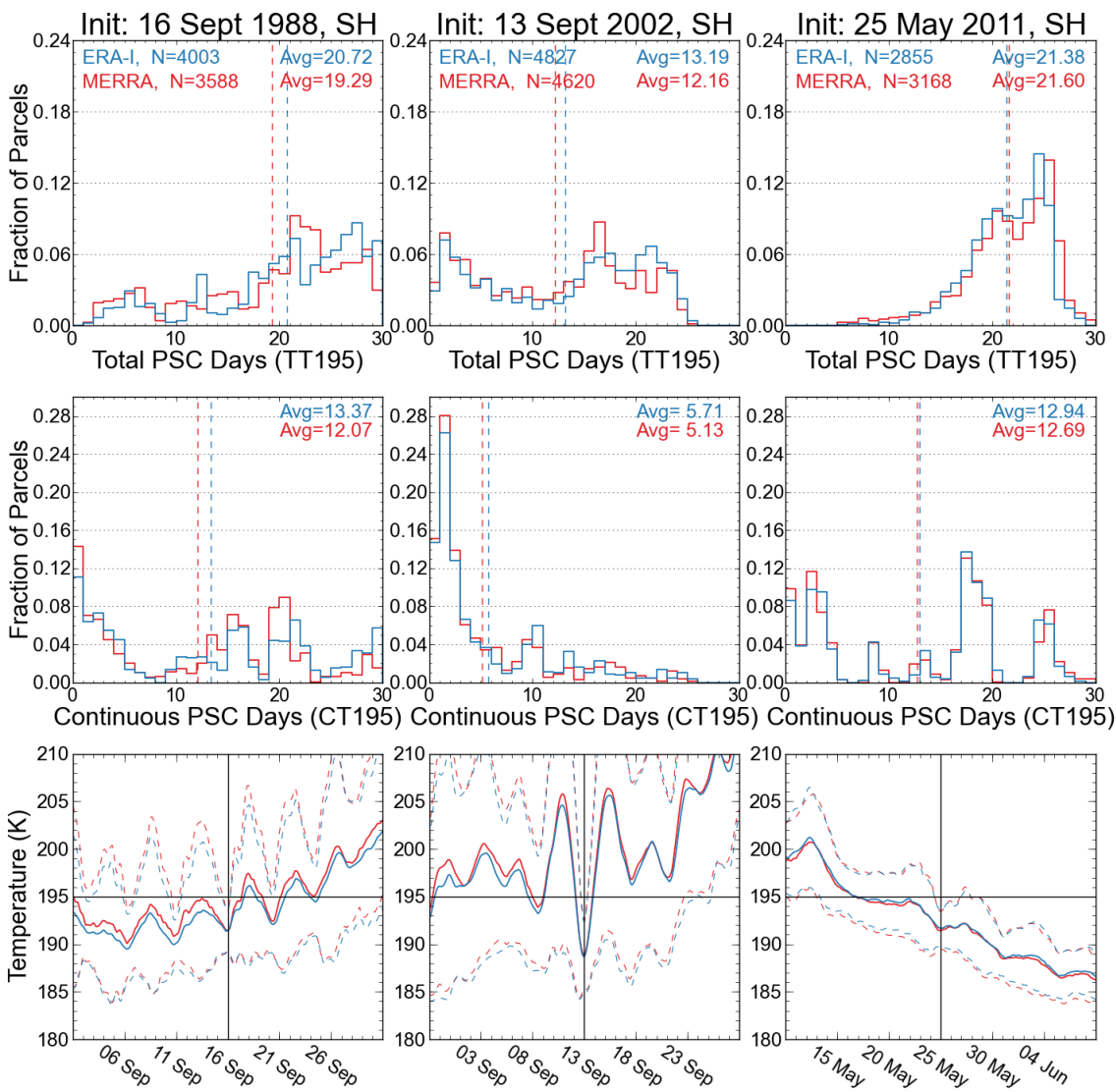

Figure 18. As in Fig. 17 but for Antarctic winters.

small differences are less critical to polar processing studies of the Southern Hemisphere than those for the Northern Hemisphere because the colder, more quiescent Antarctic winter conditions result in extensive (near total at some altitudes) Southern Hemisphere ozone destruction each year.

The patterns and evolution of the differences between MERRA and ERA-I in the Arctic are much more complicated than those in the Antarctic. The temperature diagnostics in the NH show monthly CPADs decreasing in magnitude by a significant amount over the five observational periods studied, with, for example, maximum monthly mean differences in minimum temperature (the most sensitive diagnostic, as it relies on a single-point comparison for each day) under $1 \mathrm{~K}$ since 1998 , and no larger than $\sim 0.5 \mathrm{~K}$ after 2007. Since the development of PSCs depends critically on temperature thresholds, this close agreement means that the choice of MERRA or ERA-I data is unlikely to make a substantial difference in most polar processing studies of the Arctic or Antarctic for time periods in the past 15 or so years. In contrast, the diagnostics of the strength and size of the $\mathrm{NH}$ polar vortex show differences that either stay relatively constant or increase slightly over the years. This suggests that differences in the models and/or in the handling of the assimilated data sets can still be important factors even when the temperature fields are quite well constrained by data.

The results in this paper provide strong evidence that the agreement between MERRA and ERA-I evolves with their changing data inputs. While this is an unsurprising result, it confirms that changes in the assimilated observations often directly influence the analyzed temperature fields more than the model and assimilation characteristics do. Only when observations were sparse and nearly identical in MERRA and ERA-I (such as in the SH before 2002) did we see large differences that indicated the effect of model and assimilation system differences. Our results further indicate that ERA-I's assimilation of measurements from GPSRO and other additional instruments that are not used in MERRA in the final observation period (2007-2013) results in only a small improvement in stratospheric temperature diagnostics that already show good agreement after 2001. The most recent period has the best agreement for most of the diagnostics shown. This has been noted elsewhere: Martineau and Son (2010) found that MERRA and ERA-I had the lowest biases 
among other reanalyses relative to COSMIC temperatures during the 2009 Arctic sudden stratospheric warming.

Further work is planned to more fully characterize the agreement of diagnostics of polar processing between recent reanalyses and the importance of these diagnostics to polar processing studies. In the context of the SPARC (Stratosphere-troposphere Processes And their Role in Climate) Reanalysis Intercomparison Project (S-RIP; see http: //s-rip.ees.hokudai.ac.jp/index.html), we plan to extend these intercomparisons to include the NCEP Climate Forecast System Reanalysis (NCEP/CFSR, Saha et al., 2010) and the Japanese 55-year Reanalysis (JRA55, Kobayashi et al., 2015); these reanalyses, like MERRA and ERA-I, are recent high-resolution data sets that are valuable for numerous studies, including those of polar processing. In addition, two of the diagnostics introduced (sunlit vortex area and VTC) have not been widely used in previous polar processing studies. Work applying the sunlit vortex area and VTC diagnostics to disturbed and quiescent Arctic winters is in progress and will help establish the sensitivity of polar processing and ozone loss to the conditions characterized by these diagnostics.

Acknowledgements. The authors would like to thank the personnel responsible for producing the ERA-Interim and MERRA reanalysis data sets. ERA-Interim data were made available by ECMWF, Shinfield Park, Reading, UK; MERRA data were provided by the GMAO, Greenbelt, Maryland, USA. Thanks to David Tan, Steven Pawson, and our reviewers, S. Chabrillat and C. Long, for their helpful comments and suggestions regarding this work; N. Livesey for help with setting up the trajectory code; and B. Knosp, W. Daffer, and the JPL Microwave Limb Sounder team for computing and data management support. Work at the Jet Propulsion Laboratory, California Institute of Technology, was done under contract with the National Aeronautics and Space Administration.

Edited by: W. Lahoz

\section{References}

Berrisford, P., Dee, D. P., Fielding, K., Fuentes, M., Kallberg, P., Kobayashi, S., and Uppala, S.: The ERA-Interim Archive, ERA report series, 1-16, 2009.

Bloom, S. C., Takacs, L. L., da Silva, A. M., and Ledvina, D.: Data Assimilation Using Incremental Analysis Updates, Mon. Weather Rev., 124, 1256-1271, 1996.

Brakebusch, M., Randall, C. E., Kinnison, D. E., Tilmes, S., Santee, M. L., and Manney, G. L.: Evaluation of whole atmosphere community climate model simulations of ozone during Arctic winter 2004-2005, J. Geophys. Res., 118, 2673-2688, 2013.

Charlton-Perez, A. J., Hawkins, E., Eyring, V., Cionni, I., Bodeker, G. E., Kinnison, D. E., Akiyoshi, H., Frith, S. M., Garcia, R., Gettelman, A., Lamarque, J. F., Nakamura, T., Pawson, S., Yamashita, Y., Bekki, S., Braesicke, P., Chipperfield, M. P., Dhomse, S., Marchand, M., Mancini, E., Morgenstern, O., Pitari, G., Plummer, D., Pyle, J. A., Rozanov, E., Scinocca, J., Shibata, K., Shepherd, T. G., Tian, W., and Waugh, D. W.: The potential to narrow uncertainty in projections of stratospheric ozone over the 21st century, Atmos. Chem. Phys., 10, 94739486, doi:10.5194/acp-10-9473-2010, 2010.

Coy, L. and Pawson, S.: The Major Stratospheric Sudden Warming of January 2013: Analyses and Forecasts in the GEOS-5 Data Assimilation System, Mon. Weather Rev., 143, 491-510, doi:10.1175/MWR-D-14-00023.1, 2015.

Davies, S., Chipperfield, M. P., Carslaw, K. S., Sinnhuber, B.-M., Anderson, J. G., Stimpfle, R. M., Wilmouth, D. M., Fahey, D. W., Popp, P. J., Richard, E. C., von der Gathen, P., Jost, H., and Webster, C. R.: Modeling the effect of denitrification on Arctic ozone depletion during winter 1999/2000, J. Geophys. Res., 107, 8322, doi:10.1029/2001JD000445, 2002.

Dee, D. P., Uppala, S. M., Simmons, A. J., Berrisford, P., Poli, P., Kobayashi, S., Andrae, U., Balmaseda, M. A., Balsamo, G., Bauer, P., Bechtold, P., Beljaars, A. C. M., van de Berg, L., Bidlot, J., Bormann, N., Delsol, C., Dragani, R., Fuentes, M., Geer, A. J., Haimberger, L., Healy, S. B., Hersbach, H., Hólm, E. V., Isaksen, L., Kållberg, P., Köhler, M., Matricardi, M., McNally, A. P., Monge-Sanz, B. M., Morcrette, J.-J., Park, B.-K., Peubey, C., de Rosnay, P., Tavolato, C., Thépaut, J.-N., and Vitart, F.: The ERA-Interim reanalysis: configuration and performance of the data assimilation system, Q. J. Roy. Meteor. Soc., 137, 553-597, 2011.

Dunkerton, T. J. and Delisi, D. P.: Evolution of potential vorticity in the winter stratosphere of January-February 1979, J. Geophys. Res., 91, 1199-1208, 1986.

Feng, W., Chipperfield, M. P., Roscoe, H. K., Remedios, J. J., Waterfall, A. M., Stiller, G. P., Glatthor, N., Höpfner, M., and Wang, D.-Y.: Three-dimensional model study of the Antarctic ozone hole in 2002 and comparison with 2000, J. Atmos. Sci., 62, 822837, 2005.

Feng, W., Chipperfield, M. P., Davies, S., von der Gathen, P., Kyrö, E., Volk, C. M., Ulanovsky, A., and Belyaev, G.: Large chemical ozone loss in 2004/2005 Arctic winter/spring, Geophys. Res. Lett., 34, L09803, doi:10.1029/2006GL029098, 2007.

Fueglistaler, S., Liu, Y. S., Flannaghan, T. J., Haynes, P. H., Dee, D. P., Read, W. J., Remsberg, E. E., Thomason, L. W., Hurst, D. F., Lanzante, J. R., and Bernath, P. F.: The relation between atmospheric humidity and temperature trends for stratospheric water, J. Geophys. Res., 118, 1052-1074, 2013.

Fujiwara, M., Polavarapu, S., and Jackson, D.: A Proposal of the SPARC Reanalysis/Analysis Intercomparison Project, SPARC Newsletter, 14-17, 2012.

Hanson, D. and Mauersberger, K.: Laboratory studies of the nitric acid trihydrate: Implications for the south polar stratosphere, Geophys. Res. Lett., 15, 855-858, 1988.

Harris, N. R. P., Lehmann, R., Rex, M., and von der Gathen, P.: A closer look at Arctic ozone loss and polar stratospheric clouds, Atmos. Chem. Phys., 10, 8499-8510, doi:10.5194/acp-10-84992010, 2010.

Hitchcock, P., Shepherd, T. G., and McLandress, C.: Past and future conditions for polar stratospheric cloud formation simulated by the Canadian Middle Atmosphere Model, Atmos. Chem. Phys., 9, 483-495, doi:10.5194/acp-9-483-2009, 2009.

Knox, J. A.: On converting potential temperature to altitude in the middle atmosphere, Eos Trans. AGU, 79, 376-378, 1998.

Kobayashi, S., Ota, Y., Harada, Y., Ebita, A., Moriya, M., Onoda, H., Onogi, K., Kamahori, H., Kobayashi, C., Endo, H., Miyaoka, 
K., and Takahashi, K.: The JRA-55 Reanalysis: General Specification and Basic Characteristics, J. Meteorol. Soc. Jpn., 93, 5-48, doi:10.2151/jmsj.2015-001, 2015.

Lahoz, W. A. and Schneider, P.: Data Assimilation: Making Sense of Earth Observation, Frontiers in Environmental Science, 2, 6, doi:10.3389/fenvs.2014.00016, 2014.

Livesey, N. J., Santee, M. L., and Manney, G. L.: A Match-based approach to the estimation of polar stratospheric ozone loss using Aura Microwave Limb Sounder observations, Atmos. Chem. Phys. Discuss., 15, 10041-10083, doi:10.5194/acpd-15-100412015, 2015.

Lucchesi, R.: File Specification for MERRA products, GMAO Office Note No. 1 (Version 2.3), available at: http://gmao.gsfc.nasa. gov/pubs/office_notes/, 2012.

Mann, G. W., Davies, S., Carslaw, K. S., Chipperfield, M. P., and Kettleborough, J.: Polar vortex concentricity as a controlling factor in Arctic denitrification, J. Geophys. Res., 107, 4663, doi:10.1029/2002JD002102, 2002.

Manney, G. L., Zurek, R. W., Gelman, M. E., Miller, A. J., and Nagatani, R.: The anomalous Arctic lower stratospheric polar vortex of 1992-1993, Geophys. Res. Lett., 21, 2405-2408, 1994a.

Manney, G. L., Zurek, R. W., O'Neill, A., and Swinbank, R.: On the motion of air through the stratospheric polar vortex, J. Atmos. Sci., 51, 2973-2994, 1994b.

Manney, G. L., Sabutis, J. L., Pawson, S., Santee, M. L., Naujokat, B., Swinbank, R., Gelman, M. E., and Ebisuzaki, W.: Lower stratospheric temperature differences between meteorological analyses in two cold Arctic winters and their impact on polar processing studies, J. Geophys. Res., 108, 8328, doi:10.1029/2001JD001149, 2003.

Manney, G. L., Allen, D. R., Krüger, K., Naujokat, B., Santee, M. L., Sabutis, J. L., Pawson, S., Swinbank, R., Randall, C. E., Simmons, A. J., and Long, C.: Diagnostic Comparison of Meteorological Analyses during the 2002 Antarctic Winter, Mon. Weather Rev., 133, 1261-1278, 2005a.

Manney, G. L., Krüger, K., Sabutis, J. L., Sena, S. A., and Pawson, S.: The remarkable 2003-2004 winter and other recent warm winters in the Arctic stratosphere since the late 1990s, J. Geophys. Res., 110, D04107, doi:10.1029/2004JD005367, 2005b.

Manney, G. L., Daffer, W. H., Zawodny, J. M., Bernath, P. F., Hoppel, K. W., Walker, K. A., Knosp, B. W., Boone, C., Remsberg, E. E., Santee, M. L., Harvey, V. L., Pawson, S., Jackson, D. R., Deaver, L., McElroy, C. T., McLinden, C. A., Drummond, J. R., Pumphrey, H. C., Lambert, A., Schwartz, M. J., Froidevaux, L., McLeod, S., Takacs, L. L., Suarez, M. J., Trepte, C. R., Cuddy, D. C., Livesey, N. J., Harwood, R. S., and Waters, J. W.: Solar occultation satellite data and derived meteorological products: Sampling issues and comparisons with Aura Microwave Limb Sounder, J. Geophys. Res., 112, doi:10.1029/2007JD008709, 2007.

Manney, G. L., Santee, M. L., Rex, M., Livesey, N. J., Pitts, M. C., Veefkind, P., Nash, E. R., Wohltmann, I., Lehmann, R., Froidevaux, L., Poole, L. R., Schoeberl, M. R., Haffner, D. P., Davies, J., Dorokhov, V., Gernandt, H., Johnson, B., Kivi, R., Kyrö, E., Larsen, N., Levelt, P. F., Makshtas, A., McElroy, C. T., Nakajima, H., Parrondo, M. C., Tarasick, D. W., von der Gathen, P., Walker, K. A., and Zinoviev, N. S.: Unprecedented Arctic Ozone Loss in 2011, Nature, 478, 469-475, 2011.
Martineau, P. and Son, S.-W.: Quality of reanalysis data during stratospheric vortex weakening and intensification events, Geophys. Res. Lett., 37, L22801, doi:10.1029/2010GL045237, 2010.

McNally, A. P., Watts, P. D., A. Smith, J., Engelen, R., Kelly, G. A., Thépaut, J. N., and Matricardi, M.: The assimilation of AIRS radiance data at ECMWF, Q. J. Roy. Meteor. Soc., 132, 935-957, doi:10.1256/qj.04.171, 2006.

Mitchell, D. M., Charlton-Perez, A. J., and Gray, L. J.: Characterizing the Variability and Extremes of the stratospheric polar vortices using 2-D moment analysis, J. Atmos. Sci., 68, 1194-1213, 2011.

Pawson, S.: Representation of the Middle-to-Upper Stratosphere in MERRA, Global Modeling and Assimilation Office Annual Report \& Research Highlights, 42-43, 2012.

Pawson, S. and Naujokat, B.: The cold winters of the middle 1990s in the northern lower stratosphere, J. Geophys. Res., 104, 14209$14222,1999$.

Pommereau, J.-P., Goutail, F., Lefèvre, F., Pazmino, A., Adams, C., Dorokhov, V., Eriksen, P., Kivi, R., Stebel, K., Zhao, X., and van Roozendael, M.: Why unprecedented ozone loss in the Arctic in 2011? Is it related to climate change?, Atmos. Chem. Phys., 13, 5299-5308, doi:10.5194/acp-13-5299-2013, 2013.

Rex, M., Von Der Gathen, P., Braathen, G., Harris, N., Reimer, E., Beck, A., Alfier, R., Kr"uger-carstensen, R., Chipperfield, M., De Backer, H., Balis, D., O'Connor, F., Dier, H., Dorokhov, V., Fast, H., Gamma, A., Gil, M., Kyrö, E., Litynska, Z., Mikkelsen, I., Molyneux, M., Murphy, G., Reid, S., Rummukainen, M., and Zerefos, C.: Chemical Ozone Loss in the Arctic Winter 1994/95 as Determined by the Match Technique, J. Atmos. Chem., 32, 35-59, doi:10.1023/A:1006093826861, 1999.

Rex, M., Salawitch, R. J., Gathen, P., Harris, N. R., Chipperfield, M. P., and Naujokat, B.: Arctic ozone loss and climate change, Geophys. Res. Lett., 31, L04116, doi:10.1029/2003GL018844, 2004.

Rex, M., Salawitch, R. J., Deckelmann, H., von der Gathen, P., Harris, N. R. P., Chipperfield, M. P., Naujokat, B., Reimer, E., Allart, M., Andersen, S. B., Bevilacqua, R., Braathen, G. O., Claude, H., Davies, J., De Backer, H., Dier, H., Dorokhov, V., Fast, H., Gerding, M., Godin-Beekmann, S., Hoppel, K., Johnson, B., Kyrö, E., Litynska, Z., Moore, D., Nakane, H., Parrondo, M. C., Risley, A. D., Skrivankova, P., St"ubi, R., Viatte, P., Yushkov, V., and Zerefos, C.: Arctic winter 2005: Implications for stratospheric ozone loss and climate change, Geophys. Res. Lett., 33, L23808, doi:10.1029/2006GL026731, 2006.

Rieder, H. and Polvani, L. M.: Are recent Arctic ozone losses caused by increasing greenhouse gases?, Geophys. Res. Lett., 40, 4437-4441, 2013.

Rienecker, M. M., Suarez, M. J., Gelaro, R., Todling, R., Bacmeister, J., Liu, E., Bosilovich, M. G., Schubert, S. D., Takacs, L., Kim, G.-K., Bloom, S., Chen, J., Collins, D., Conaty, A., Da Silva, A., Gu, W., Joiner, J., Koster, R. D., Lucchesi, R., Molod, A., Owens, T., Pawson, S., Pegion, P., Redder, C. R., Reichle, R., Robertson, F. R., Ruddick, A. G., Sienkiewicz, M., and Woollen, J.: MERRA: NASA's modern-era retrospective analysis for research and applications, J. Climate, 24, 3624-3648, 2011.

Saha, S., Moorthi, S., Pan, H.-L., Wu, X., Wang, J., Nadiga, S., Tripp, P., Kistler, R., Woollen, J., Behringer, D., Liu, H., Stokes, D., Grumbine, R., Gayno, G., Wang, J., Hou, Y.-T., Chuang, H.Y., Juang, H.-M. H., Sela, J., Iredell, M., Treadon, R., Kleist, 
D., Delst, P. V., Keyser, D., Derber, J., Ek, M., Meng, J., Wei, H., Yang, R., Lord, S., van den Dool, H., Kumar, A., Wang, W., Long, C., Chelliah, M., Xue, Y., Huang, B., Schemm, J.-K., Ebisuzaki, W., Lin, R., Xie, P., Chen, M., Zhou, S., Higgins, W., Zou, C.-Z., Liu, Q., Chen, Y., Han, Y., Cucurull, L., Reynolds, R. W., Rutledge, G., and Goldberg, M.: The NCEP Climate Forecast System Reanalysis, B. Am. Meteorol Soc., 91, 1015-1057, 2010.

Santee, M. L., Tabazadeh, A., Manney, G. L., Fromm, M. D., Jensen, E. J., Bevilacqua, R. M., and Waters, J. W.: A Lagrangian approach to studying Arctic polar stratospheric clouds using UARS MLS $\mathrm{HNO}_{3}$ and POAM II aerosol extinction measurements, J. Geophys. Res., 107, ACH 41-ACH 413, doi:10.1029/2000JD000227, 2002.

Schoeberl, M. R. and Dessler, A. E.: Dehydration of the stratosphere, Atmos. Chem. Phys., 11, 8433-8446, doi:10.5194/acp11-8433-2011, 2011.

Schoeberl, M. R., Lait, L. R., Newman, P. A., and Rosenfield, J. E.: The structure of the polar vortex, J. Geophys. Res., 97, 78597882, 1992.

Schwartz, M. J., Lambert, A., Manney, G. L., Read, W. G., Livesey, N. J., Froidevaux, L., Ao, C. O., Bernath, P. F., Boone, C. D., Cofield, R. E., Daffer, W. H., Drouin, B. J., Fetzer, E. J., Fuller, R. A., Jarnot, R. F., Jiang, J. H., Jiang, Y. B., Knosp, B. W., Kr"uger, K., Li, J.-L. F., Mlynczak, M. G., Pawson, S., Russell, J. M., Santee, M. L., Snyder, W. V., Stek, P. C., Thurstans, R. P., Tompkins, A. M., Wagner, P. A., Walker, K. A., Waters, J. W., and Wu, D. L.: Validation of the Aura Microwave Limb Sounder temperature and geopotential height measurements, J. Geophys. Res., 113, D15, doi:10.1029/2007JD008783, 2008.

Seviour, W. J. M., Mitchell, D. M., and Gray, L. J.: A practical method to identify displaced and split stratospheric polar vortex events, Geophys. Res. Lett., 40, 5268-5273, doi:10.1002/grl.50927, 2013.

Sica, R. J., Izawa, M. R. M., Walker, K. A., Boone, C., Petelina, S. V., Argall, P. S., Bernath, P., Burns, G. B., Catoire, V., Collins, R. L., Daffer, W. H., De Clercq, C., Fan, Z. Y., Firanski, B. J., French, W. J. R., Gerard, P., Gerding, M., Granville, J., Innis, J. L., Keckhut, P., Kerzenmacher, T., Klekociuk, A. R., Kyrö, E., Lambert, J. C., Llewellyn, E. J., Manney, G. L., McDermid, I. S., Mizutani, K., Murayama, Y., Piccolo, C., Raspollini, P., Ridolfi, M., Robert, C., Steinbrecht, W., Strawbridge, K. B., Strong, K., Stübi, R., and Thurairajah, B.: Validation of the Atmospheric Chemistry Experiment (ACE) version 2.2 temperature using ground-based and space-borne measurements, Atmos. Chem. Phys., 8, 35-62, doi:10.5194/acp-8-35-2008, 2008.
Simmons, A. J., Hortal, M., Kelly, G., McNally, A., Untch, A., and Uppala, S.: ECMWF analyses and forecasts of stratospheric winter polar vortex break-up: September 2002 in the southern hemisphere and related events, J. Atmos. Sci., 62, 668-689, 2005.

Simmons, A. J., Poli, P., Dee, D. P., Berrisfordand, P., Hersbach, H., Kobayashi, S., and Peubey, C.: Estimating low-frequency variability and trends in atmospheric temperature using ERAInterim, Q. J. Roy. Meteor. Soc., 140, 329-353, 2014.

Sinnhuber, B.-M., Stiller, G., Ruhnke, R., von Clarmann, T., Kellmann, S., and Aschmann, J.: Arctic winter 2010/2011 at the brink of an ozone hole, Geophys. Res. Lett., 38, L24814, doi:10.1029/2011GL049784, 2011.

Solomon, S.: Stratospheric ozone depletion: A review of concepts and history, Rev. Geophys., 37, 275-316, 1999.

Strahan, S. E., Douglass, A. R., and Newman, P. A.: The contributions of chemistry and transport to low Arctic ozone in March 2011 derived from Aura MLS observations, J. Geophys. Res., 118, 1563-1576, doi:10.1002/jgrd.50181, 2013.

Tilmes, S., Müller, R., Engel, A., Rex, M., and Russel, J. M.: Chemical ozone loss in the Arctic and Antarctic stratosphere between 1992 and 2005, Geophys. Res. Lett., 33, L20812, doi:10.1029/2006GL026925, 2006.

Waugh, D. W. and Randel, W. J.: Climatology of Arctic and Antarctic polar vortices using elliptical diagnostics, J. Atmos. Sci., 56, 1594-1613, 1999.

Wegner, T., Grooß, J.-U., von Hobe, M., Stroh, F., Sumin'skaEbersoldt, O., Volk, C. M., Hösen, E., Mitev, V., Shur, G., and Müller, R.: Heterogeneous chlorine activation on stratospheric aerosols and clouds in the Arctic polar vortex, Atmos. Chem. Phys., 12, 11095-11106, doi:10.5194/acp-12-11095-2012, 2012.

WMO: Scientific assessment of ozone depletion: 2010, Global Ozone Res. and Monit. Proj. Rep. 52, Geneva, Switzerland, 2011.

WMO: Scientific assessment of ozone depletion: 2014, Global Ozone Res. and Monit. Proj. Rep. 55, Geneva, Switzerland, 2015.

Wohltmann, I., Wegner, T., Müller, R., Lehmann, R., Rex, M., Manney, G. L., Santee, M. L., Bernath, P., Sumin'ska-Ebersoldt, O., Stroh, F., von Hobe, M., Volk, C. M., Hösen, E., Ravegnani, F., Ulanovsky, A., and Yushkov, V.: Uncertainties in modelling heterogeneous chemistry and Arctic ozone depletion in the winter 2009/2010, Atmos. Chem. Phys., 13, 3909-3929, doi:10.5194/acp-13-3909-2013, 2013. 